\title{
Organic functional groups in aerosol particles from burning and non-burning forest emissions at a high-elevation mountain site
}

\author{
S. Takahama1 ${ }^{1}$, R. E. Schwartz ${ }^{1}$, L. M. Russell ${ }^{1}$, A. M. Macdonald ${ }^{2}$, S. Sharma ${ }^{2}$, and W. R. Leaitch ${ }^{2}$ \\ ${ }^{1}$ Scripps Institution of Oceanography, University of California San Diego, La Jolla, CA, USA \\ ${ }^{2}$ Environment Canada, Sci. Technol. Branch, Toronto, ON, Canada
}

Received: 12 December 2010 - Published in Atmos. Chem. Phys. Discuss.: 24 January 2011

Revised: 24 May 2011 - Accepted: 21 June 2011 - Published: 6 July 2011

\begin{abstract}
Ambient particles collected on teflon filters at the Peak of Whistler Mountain, British Columbia (2182 m a.s.l.) during spring and summer 2009 were measured by Fourier transform infrared (FTIR) spectroscopy for organic functional groups (OFG). The project mean and standard deviation of organic aerosol mass concentrations $(\mathrm{OM})$ for all samples was $3.2 \pm 3.3\left(\mu \mathrm{g} \mathrm{m}^{-3}\right)$. Measurements of aerosol mass fragments, size, and number concentrations were used to separate fossil-fuel combustion and burning and non-burning forest sources of the measured organic aerosol. The OM was composed of the same anthropogenic and non-burning forest components observed at Whistler mid-valley in the spring of 2008; during the 2009 campaign, biomass burning aerosol was additionally observed from fire episodes occurring between June and September. On average, organic hydroxyl, alkane, carboxylic acid, ketone, and primary amine groups represented $31 \% \pm 11 \%, 34 \% \pm 9 \%, 23 \% \pm 6 \%, 6 \% \pm 7 \%$, and $6 \% \pm 3 \%$ of OM, respectively. Ketones in aerosols were associated with burning and non-burning forest origins, and represented up to $27 \%$ of the OM. The organic aerosol fraction resided almost entirely in the submicron fraction without significant diurnal variations. $\mathrm{OM} / \mathrm{OC}$ mass ratios ranged mostly between 2.0 and 2.2 and $\mathrm{O} / \mathrm{C}$ atomic ratios between 0.57 and 0.76 , indicating that the organic aerosol reaching the site was highly aged and possibly formed through secondary formation processes.
\end{abstract}

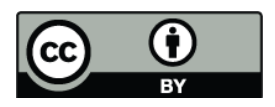

Correspondence to: L. M. Russell (lmrussell@ucsd.edu)

\section{Introduction}

Burning and non-burning forest emissions are important contributors to primary and secondary organic mass (OM) (Bond et al., 2004; Hallquist et al., 2009). Bond et al. (2004) name biomass burning (BB) as the largest (42\%) combustion source of primary organic carbon, outweighing both fossil fuel (38\%) and biofuel (20\%) combustion, and accounting for 31 to $45 \mathrm{TgC} \mathrm{yr}^{-1}$ of the global primary organic aerosol (POA). Gas phase compounds also result in significant aerosol formation (secondary organic aerosol, SOA). Globally, biogenic volatile organic compounds (BVOCs) emissions may be 10 times greater than anthropogenic VOC emissions (Seinfeld and Pandis, 2006). Oxidation of BVOCs yields a large biogenic contribution to SOA, with estimates ranging from 12 to $70 \mathrm{Tg} \mathrm{C} \mathrm{yr}^{-1}$ (Hallquist et al., 2009). Large mass contributions from sugars and homologous alkane and alkene compounds, have previously been reported by Fine et al. (2002) and Simoneit (2002) (among others) for products of various types of wood or wildfire (plant) burning using gas-chromatography with mass spectrometry (GC-MS). These methods typically report compounds identified from mass fragments, along with an unrecovered portion comprising an unresolved complex mixture (UCM) thought to be primarily ring-structured compounds, and another set of unidentified compounds (unextractable or unelutable) for which structures are not proposed. Levoglucosan, a thermal breakdown product of cellulose, is often used as a biomass burning marker (Simoneit et al., 1999). Levoglucosan is additionally measured by ion chromatography (Sullivan et al., 2008) or aerosol mass spectrometry (Lee et al., 2010), and has been suggested to contribute from a few to a quarter percent of the organic aerosol mass (Fine et al., 2002; Sullivan et al., 2008). There are also many

Published by Copernicus Publications on behalf of the European Geosciences Union. 
uncertainties regarding the composition of the organic fraction of BB aerosol, which are dependent on fuel type, burning phase (flaming or smoldering), and also the transformation through aging that occurs. Reid et al. (2005) provides a review on the rapid growth in particle size, recondensation of low-volatility products, and condensation of oxidized (presumably more polar and hydrophilic) products, increasing the aerosol hygroscopicity. The oxygenated fraction of BB aerosol is also reported to change with age. Levoglucosan (and presumably other anhydrous sugars) are reported to degrade in BB plumes (Hennigan et al., 2010, 2011; Cubison et al., 2011), while mass ratios of organic acid to carbonyl are reported to increase with age of airmass in BB plumes Hawkins and Russell (2010).

These significant forest-related emissions present a complex issue for climate prediction due to a number of possible feedbacks. Large uncontrollable fires are expected to increase with climate change (IPCC, 2007) due to reduced rainfall and increased temperatures. Bowman et al. (2009) discuss how fires in turn influence climate due to their large greenhouse gas $\left(\mathrm{CO}_{2}\right.$ emissions equal to $50 \%$ of those from fossil-fuel combustion) and aerosol particle (40\% of black carbon, along with large POA emissions discussed) emissions. Kulmala et al. (2004) explores feedbacks between climate and non-burning forest emissions. They present evidence that increased temperatures and $\mathrm{CO}_{2}$ concentrations will act to fertilize forests, which will in turn create a large BVOC source and ultimately result in a cooling effect from the increased biogenic aerosol.

The radiative impacts of aerosol particles are altitudedependent (Penner et al., 2003). Chuang et al. (2002) estimated the forcing from the first indirect effect associated with organic aerosol from $\mathrm{BB}$ to be $-1.16 \mathrm{~W} \mathrm{~m}^{-2}$. Injection of aerosol particles higher in the atmosphere can increase particle lifetime and thus their ability to influence climate. Higher-altitude injections of organic BB aerosol may absorb longwave radiation, leading to negative forcing (Penner et al., 2003). Additionally, global chemical transport models have been reported to under-predict organic aerosol in the free troposphere by 10-100 times when compared to ambient measurements (Heald et al., 2005) during the ACEAsia campaign (NW Pacific, 2001), though reported modelmeasurement discrepancies were much lower when large contributions from biomass burning and biogenic SOA were simulated for the ICARTT campaign measurements (northeastern North America, 2004) (Heald et al., 2006).

Measurements in the free troposphere (FT) can provide information regarding background concentrations (e.g., Nyeki et al., 1998) and detect pollutants transported over long distances (e.g., Leaitch et al., 2009), and yet multi-seasonal records of high-altitude measurements of organic aerosol composition in the FT are sparse. Researchers at one monitoring station, Jungfraujoch, located in the Swiss Alps ( $\sim 3500 \mathrm{~m}$ a.s.1.), have summarized measurements of interannual, seasonal, and diurnal variations of aerosol at the site from their long-term measurement program, reporting vertical transport of airmasses from the boundary layer between late spring and late summer (Lugauer et al., 1998) and higher aerosol concentrations during these months, with the $\mathrm{PM}_{1}$ mass primarily composed of organic and sulphate aerosol with smaller contributions from nitrate, ammonium, and black carbon (Cozic et al., 2008).

Functional group analysis by FTIR provides several useful characterizations for organic aerosol measurements. By using the full dimensionality of the feature vector (i.e., the full infrared spectrum that we analyze) in a factor-analytic decomposition of ambient aerosol spectra, component profiles have been shown to retain distinguishing spectral features which have been related to original sources of organic aerosols (Russell et al., 2011). A reduced representation of the FTIR spectrum in molar quantities of functional groups is physically meaningful to the extent that it has been linked to predictive models of molecular interactions in the condensed phase within an established thermodynamic framework (i.e., activity coefficients), from which hygroscopic properties and volatilities can be estimated.

In this study, we report on organic functional group (OFG) concentrations and composition at a lower free troposphere, high-elevation mountain site in Whistler, British Columbia, measured during spring and summer 2009. The campaign captured regional influences of burning and non-burning forest emissions, and a long-range transport episode impacting the aerosol concentrations at the site. The observed composition is contrasted with organic aerosol measurements influenced by similar sources at a lower elevation site in Whistler and other locations where FTIR measurements have been reported.

\section{Methods}

\subsection{Sampling site}

Since 2002, Environment Canada (EC) has conducted atmospheric composition measurements at Whistler Peak in the lower troposphere (2182 $\mathrm{m}$ a.s.l.) (Macdonald et al., 2006). Some of the objectives of the site are to monitor changes in the composition and concentration of particulate pollutants entering North America from Asia, document the aerosol in the free troposphere, and study the forest aerosol. The present sampling campaign consists of measurements from 26 March 2009 to 27 April 2009 and 23 May 2009 to 10 September 2009 (which roughly correspond to spring and summer seasons). The break in between was due to a logistical interruption in operations.

\subsection{Aerosol sampling inlet}

The ambient aerosol particles were delivered into the instrument room through a stainless steel manifold with an open intake covered above by a slightly conical hat. The 
flow through the $7.3 \mathrm{~cm}$ ID manifold is approximately $1201 \mathrm{~min}^{-1}$, equivalent to a speed of about $0.5 \mathrm{~m} \mathrm{~s}^{-1}$. The manifold is about $6 \mathrm{~m}$ total length and therefore the average residence time is about $12 \mathrm{~s}$. The transfer time from the manifold to each instrument is $<1 \mathrm{~s}$. At the end of the manifold, particles are sampled from near the centre of the flow to minimize wall losses of primarily ultrafine particles. Losses of coarse particles are primarily defined by the horizontal wind speeds at the intake point, and previous comparisons with other measurements suggest that particles of at least $6 \mu \mathrm{m}$ diameter are sampled with efficiency equivalent to the measurement uncertainty. The intake of the manifold is heated to a minimum of $4{ }^{\circ} \mathrm{C}$ in order to prevent riming of the intake when supercooled cloud is present. The aerosol drawn down the manifold into the room housing the instruments is further warmed up to as much as $20^{\circ} \mathrm{C}$. In the case of the filters for the OFG analysis this warming is momentary as the aerosol was collected onto filters housed in a refrigerator held at a temperature of approximately $4^{\circ} \mathrm{C}$, to reduce losses from volatilization over multiple-day exposure periods. The sampling line connecting the filters to the manifold was nearly vertical and about $1 \mathrm{~m}$ of $1 \mathrm{~cm}$ ID stainless steel tubing.

\subsection{Organic functional group composition}

Atmospheric particles were sampled on teflon filters and analyzed by Fourier transform infrared (FTIR) spectroscopy and $\mathrm{X}$-ray fluorescence (XRF) techniques for organic functional group (OFG) and elemental composition. Over a sampling period of approximately three to five days, five filter samples were collected, with three measurements collected simultaneously on $37 \mathrm{~mm}$ Teflon filters (Pall Inc.). The filter collection was divided by size into total and submicron filters, and by day and night samples with an automated switch occurring at 06:30 and 18:30 PST daily. The total samples were collected from an inlet with no size-selection. Total samples can be considered to include collection of particles up to $10 \mu \mathrm{m}$ with the absolute upper limit dependent on ambient conditions, such as wind speed and precipitation. Submicron samples were collected downstream of a $1 \mu \mathrm{m}$ impactor (Brechtel Manufacturing, Inc., Hayward, CA). A full-day filter type (sampling through both day and night) was changed from having a submicron to total sizecut on 29 May 2009. Samples were kept frozen until analysis by FTIR spectroscopy. The filters were equilibrated in a temperature and humidity-controlled cleanroom environment for $24 \mathrm{~h}$ before FTIR spectroscopic analysis. FTIR sample spectra were measured with a Tensor 27 spectrometer (Bruker, Billerica, MA), and baselined and fitted with peaks to identify OFG using the method described by Maria et al. (2003), Russell (2003), and Russell et al. (2009). Using this method, FTIR spectroscopy provides OFG concentrations, including alkane, carboxylic acid, organic hydroxyl, primary amine, carbonyl, alkene, and aromatic groups, through chemical bond-based measurements in atmospheric particles collected on a substrate (Russell et al., 2009). Alkene, aromatic, and organonitrate groups were below detection limit for all samples. Our discussion of OM will therefore neglect these compounds; their contribution to the actual OM is estimated to be between $2-5 \%$. Organosulphate groups were above detection limit during only one three day-long sampling period. Ketone group contributions are estimated from a comparison of moles of carboxylic $\mathrm{C}-\mathrm{OH}$ and total carbonyl quantified; non-acid carbonyl (including aldehydes and ketones) are determined by the moles of carbonyl present in excess of quantified moles of carboxylic C-OH. The moles of carboxylic $\mathrm{C}-\mathrm{OH}$ and carbonyl for which carbonyl was not determined to be in excess had a correlation coefficient $(r)$ of 0.84 and a regression slope of 1.0. The non-acid carbonyl is determined to be ketonic rather than aldehyde carbonyl, as absorption bands between $2700 \mathrm{~cm}^{-1}$ and $2860 \mathrm{~cm}^{-1}$ indicative of aldehydic hydrogen were not observed in the Whistler Peak spectra. The quantified non-acid carbonyl will therefore be referred to as ketones in this manuscript. The uncertainty and detection limit of ketones are therefore estimated through a contribution of the estimated carboxylic $\mathrm{C}-\mathrm{OH}$ and total carbonyl (Russell et al., 2009). Further details regarding the interpretation of spectra for apportioning absorbance to moles of bond or functional group, with respective detection limits, are provided by Maria et al. (2003) and Russell et al. (2009). Estimation of mass from these quantities is based on the analysis by Russell (2003), where moles of measured bonds are converted to the moles of comprising atoms, and values of $\mathrm{OM}$ are calculated from the sum of moles of atoms multiplied by their respective molecular weights. Using this approach, the uncertainty in OM has been calculated to be on the order of $23 \%$ (Russell, 2003).

\subsection{Elemental analysis}

XRF analysis provides quantitative measurements of elemental composition. Ninety of the same filter samples used for FTIR, the majority of which are submicron samples, were sent to Chester LabNet (Tigard, Oregon) for elemental analysis of elements $\mathrm{Na}$ and heavier (Maria et al., 2003).

\subsection{Spectromicroscopy}

Scanning Transmission X-Ray Microscopy with Near-Edge X-Ray Absorption Fine Structure (STXM-NEXAFS; Stöhr, 1992) with processing algorithms described by Takahama et al. (2010) was also used to examine single particle morphology and composition for a limited number of particles. With this method, X-rays generated at the Advanced Light Source at Lawrence Berkeley National Laboratories (Beamline 5.3.2) are used to probe the electronic structure of individual particles at a spatial resolution of approximately $30 \mathrm{~nm}$. Collectively, 30 particles from samples collected on 1 August 2009, 16:53-17:13 and 21 August 2009, 16:14-16:39, were analyzed. 


\subsection{Particle number concentrations}

Particle number concentrations were measured using a TSI 3025 Ultrafine Condensation Particle Counter (UCPC) throughout the study. Particle size distributions from $0.01 \mu \mathrm{m}$ to $0.5 \mu \mathrm{m}$ diameter were measured with a MSP Wide-range Particle Spectrometer (WPS; Liu et al., 2010) until June 28 and a TSI 3034 Scanning Mobility Particle System (3034SMPS) from 1-31 August; malfunctions terminated measurements in both cases. The WSP contains a Scanning Mobility Spectrometer (SMS) for particle measurement from 0.01 to $0.5 \mu \mathrm{m}$ and a Laser Particle Spectrometer (LPS) for measurement in the 0.5 to $10 \mu \mathrm{m}$ range. Despite the malfunction of the SMS on June 28, the LPS continued to operate and particle size distributions from 0.5 to $10 \mu \mathrm{m}$ were measured with the LPS throughout the study period. The LPS data are based on the manufacturer's calibration using polystyrene latex particles (PSLs; real refractive index of 1.585), but here we only use the data to estimate the number concentrations of supermicron particles. The SMS and the 3034-SMPS measurements are based on particle mobility in an electric field. Sizing by the SMS and 3034-SMPS was verified on site using a TSI 3071 Electrostatic Classifier calibrated with PSLs, and operated with a sheath to sample flowrate ratio of 10:1 (Knutson and Whitby, 1975). Comparisons of 30-min averaged total particle number concentrations from the UCPC with the 3034 during situations when particles were $<20 \mathrm{~nm}$ diameter are $<3 \%$ of the total, which included BB aerosols, show the particle concentration measurements agree to within $10 \%$ and on average differ by $5 \%$. The same comparison of the SMS and the UCPC indicate the SMS co-varied but was biased low relative to the UCPC by about $20 \%$ on average.

\subsection{Black carbon number concentrations}

A Single Particle Soot Photometer (SP2; Droplet Measurement Technologies, Inc.) was installed at Whistler Peak in early July. Aerosol particles are sampled into the cavity of a Nd:YAG lasing crystal $(1064 \mathrm{~nm})$ where the particles containing black carbon (BC) absorb the energy and thermally irradiate as they vapourise at approximately $4000 \mathrm{~K}$. The emitted thermal radiation (at visible wavelengths) is detected with red and blue sensitive photomultipliers. A comprehensive discussion of the SP2 operation and calibration is given by Schwarz et al. (2010). A linear calibration curve was generated by SP2 response to particles atomized from "Aquadag" in solution and size selecting them by using a TSI Electrostatic Classifier. The results also indicated a lower size threshold for detection of a BC particle of about 110nm mobility diameter. PAPI software developed by DMT was used for the data analysis. The details of PAPI software performance and evaluations with other methods have been described by Subramanian et al. (2010) and Cross et al. (2010).

\subsection{Non-refractory organic and inorganic mass concentrations}

An Aerodyne Aerosol Chemical Speciation Monitor (ACSM; Ng et al., 2011) was installed at Whistler Peak in early July, 2009. The ACSM is similar to the Aerodyne Aerosol Mass Spectrometer (AMS; Jayne et al., 2000) with the primary differences being no particle time-of-flight measurement and reduced sensitivity. The ACSM uses a Pfeiffer Prisma quadrapole and scans over 150 mass/charge $(\mathrm{m} / \mathrm{z})$ units. At Whistler Peak, the scan rate is set to $1 \mathrm{~m} / \mathrm{z}$ per second and every other scan is performed on filtered aerosol. The difference between alternate ambient and filter scans (12 scans in total) is averaged over a $30 \mathrm{~min}$ period to produce a sample data point. The ACSM uses an internal permeation source of naphthalene, identified at $m / z 128$, to provide the system constant after correction for chamber temperature. Mass calibrations are done with nearly monodisperse particles of ammonium nitrate (selected with a 10:1 sheath to sample flowrate on a TSI 3071 Electrostatic Classifier), and the relative ionisation efficiencies for sulphate and organics are based on the AMS (Ng et al., 2011). The data analysis is based on Allan et al. (2004) and Canagaratna et al. (2007), and the details are discussed by $\mathrm{Ng}$ et al. (2011). The measured detection limits for the $30 \mathrm{~min}$ averaged samples collected at Whistler peak are $40 \mathrm{ng} / \mathrm{m}^{3}$ for nitrate, $40 \mathrm{ng} / \mathrm{m}^{3}$ for sulphate and $600 \mathrm{ng} / \mathrm{m}^{3}$ for the total organic components.

\subsection{Inorganic ions analysis}

Teflon filters sampled at $16.71 \mathrm{~min}^{-1}$ over successive $48 \mathrm{~h}$ periods through a $2.5 \mu \mathrm{m}$ URG cyclone were analyzed by ion chromatography for ions of chloride, nitrate, sulphate, sodium, ammonium, and potassium.

\subsection{Comparisons of ambient and reference mass-fragment spectra}

To compare similarity - resemblance based on relative proportions of ion signals at unit mass resolution - of ambient ACSM mass spectra to reference mass spectra of dark $\alpha$-pinene ozonolysis (Shilling et al., 2009), we use the cosine angle metric-defined as $\theta=\arccos \left(\mathbf{x}^{T} \mathbf{y} /\|\mathbf{x}\|\|\mathbf{y}\|\right)$ where $\mathbf{x}$ and $\mathbf{y}$ are ion counts of two spectra (one ambient and the other reference in this case) at $m / z$ units of $43,44,57,60$, and 73 , expressed as feature vectors. The medium and high VOC loading case (spectrums (ii) and (iii) from Shilling et al., 2009) are used for comparison. The cosine angle metric is related to the Euclidean distance metric between spectra normalized by their respective dot products, and also to a measure of uncentred correlation. 
Table 1. Statistical learning methods - both supervised (known components or groups) and unsupervised (unknown components or groups) - used for analysis of FTIR spectra.

\begin{tabular}{l|cc}
\hline Task & Supervised & $\begin{array}{c}\text { Learning Method } \\
\text { Unsupervised }\end{array}$ \\
\hline Determine components & regression* & Positive Matrix Factorization*** \\
Establish groups/membership & (classification**) $^{* *}$ & hierarchical cluster analysis**** \\
\hline
\end{tabular}

\footnotetext{
* Two types of regression are used, where components are (1) known absorption patterns of functional group absorbance, and (2) spectra representing source components derived from previous studies.

** The classification problem is approached only informally; most probable labels for ambient aerosol spectra measured in this campaign are determined from comparison to previously reported spectra in the literature using visual inspection.

*** PMF (Paatero and Tapper, 1994).

**** Ward algorithm (Ward, 1963).
}

\subsection{Dimension reduction methods for FTIR analysis}

Several statistical learning methods (Hastie et al., 2009) are used to reduce the dimensionality of the ambient FTIR spectra dataset and highlight relevant patterns for interpretation (Table 1). The methods chosen reflect our emphasis in using these methods to derive physically-meaningful understanding of measurements over building models for empirical prediction. In addition to the functional group analysis discussed above, the composition and contribution of multiple components in submicron FTIR spectra were inferred by application of Positive Matrix Factorization (PMF; Paatero and Tapper, 1994), and regression analysis to the spectra matrix consisting of samples and wavenumbers in the two dimensions. PMF has been applied to FTIR spectra to identify and separate varying components (Russell et al., 2009; Hawkins and Russell, 2010; Schwartz et al., 2010). Solutions using rotation parameter FPEAK of -1.2 to 1.2 by increments of 0.6 , seed values of 1,10 , and 100 , and number of factors between two to six were examined. The Explained Variation (EV) metric is used to report what fraction or percentage of the variation in a sample spectrum is captured by the PMF components, and is defined as (Paatero, 2007)

$$
E V_{i k}=\frac{\sum_{j=1}^{m}\left|g_{i k} f_{k j}\right| / s_{i j}}{\sum_{j=1}^{m}\left(\sum_{h=1}^{p}\left|g_{i h} f_{h j}\right|+\left|e_{i j}\right|\right) / s_{i j}} \quad \forall k=1, \ldots, p
$$

where $i$ is the sample number, $k$ is the factor number, and $p$ is the number of factors chosen. $g_{i k}$ is strength or contribution of factor $k$ to the $i$-th sample, $f_{k j}$ is value (absorbance) of factor $k$ for variable (wavenumber) $j$, and $e_{i j}$ is the residual as defined in the factor analytic expression, $x_{i j}=\sum_{k=1}^{p} g_{i k} f_{k j}+e_{i j}$, where $x_{i j}$ is the absorbance for the $i$-th sample at wavenumber $j . \quad s_{i j}$ is the standard deviation matrix (or inverse squared weighting matrix) which is expressed in the objective function to be minimized, $Q=$ $\sum_{i=1}^{n} \sum_{j=1}^{m} \sum_{j} e_{i j}^{2} / s_{i j}^{2}$, subject to non-negativity constraints on $g_{i k}$ and $f_{k j}$ for $n$ samples and $m$ wavenumbers. A lack of differences among the component spectra for different rotations were observed, suggesting that the PMF solutions are robust and independent of rotation. The FPEAK $=0$ solution is used for further analysis. Regression analysis of Whistler Peak FTIR spectra was also performed to provide another means of estimating component contributions to ambient spectra. In this case, the problem statement and objective function is identical to that of PMF, but the component profiles (values of $f_{k j}$ ) are assumed a priori. Spectra from anthropogenic combustion and three (non-burning) biogenic origins derived from PMF analysis of Whistler midvalley spectra (Schwartz et al., 2010), and a BB spectrum from PMF decomposition of Scripps Pier spectra (Hawkins and Russell, 2010) were used as regressors (predictor variables). The explained variation (Eq. 1) is also used to assess the relative contributions of each component to ambient observations. While a successful PMF separation can provide average component profiles comprising the measured set of mixture samples, regression analysis eliminates some uncertainties associated with the bilinear decomposition problem of PMF by fixing the component profile matrix, provided that the profiles are complete and correct. This latter condition is found to be approximately satisfied, as the component profiles obtained from PMF are nearly identical to the set of spectra used as regressors (Sect. 3.3.2). Cluster analysis is also used to centre the discussion around a few spectra types, each of which presumably share similar histories (i.e. sources and extent of atmospheric processing). An agglomerative, hierarchical clustering algorithm outlined by (Ward, 1963 ) is applied to the ambient submicron aerosol spectra after normalizing by their respective dot products (Murphy et al., 2003). In the extreme and idealized case where a single set of components are observed at the site for each FTIR filter sampling period, PMF factors and clusters centres should be approximately identical. However, the more likely scenario is that clusters represent sets of sample mixtures containing relatively similar proportion of components; while PMF factors correspond to the elementary, statistically distinguishable components, with factor strengths indicating their relative contributions to each sample mixture. To address the questions pertaining to effectiveness of separation 


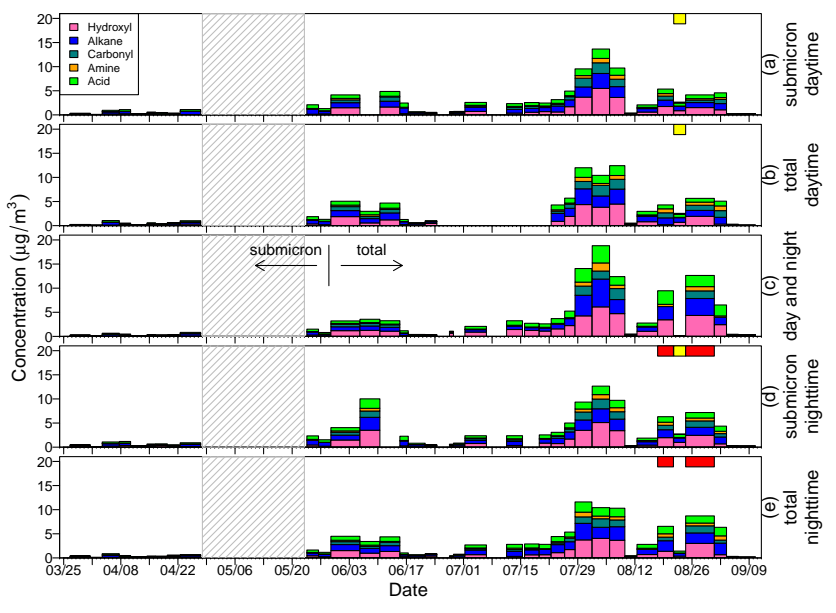

Fig. 1. Time series of OM and OFG as stacked bars: organic hydroxyl (pink), alkane (blue), ketone (teal), primary amine (orange), acid (green) in (a) day submicron, (b) day total, (c) day and night (submicron before 29 May 2009, and total post that date), (d) night submicron and, (e) night total aerosol during the 2009 sampling period. The color bar on top shows periods when supermicron aerosol was measured (red) and organosulphate groups were above detection limit (yellow).

in and understanding of PMF solutions (Paatero et al., 2002; Ulbrich et al., 2009), a combination of cluster analysis, regression, and PMF approaches is used to provide complementary information and robust interpretations to the analysis of ambient aerosol spectra.

\subsection{Backtrajectory analysis}

Potential Source Contribution Function (PSCF; Pekney et al., 2006) was also used to infer source regions from observed aerosol composition and concentrations, and airmass backtrajectories obtained from the HYbrid Single Particle Lagrangian Integrated Trajectory Model (NOAA HYSPLIT; Draxler and Rolph, 2010). Six-day backtrajectories were calculated every two hours for the duration of the campaign at heights of 10,100, and $500 \mathrm{~m}$ above ground level to consider the uncertainty of trajectories due to initial conditions. These trajectories were split according to pre-determined groups (by concentration order statistics or cluster analysis on explained variance of PMF factors).

\section{Results and Discussion}

\subsection{OM concentration and OFG composition}

The OM was composed of alkane, carboxylic acid, ketone, organic hydroxyl, and primary amine groups and was highly variable throughout the project for all sample types as shown in Fig. 1. The OM project means and standard deviations for submicron samples, total samples, and both

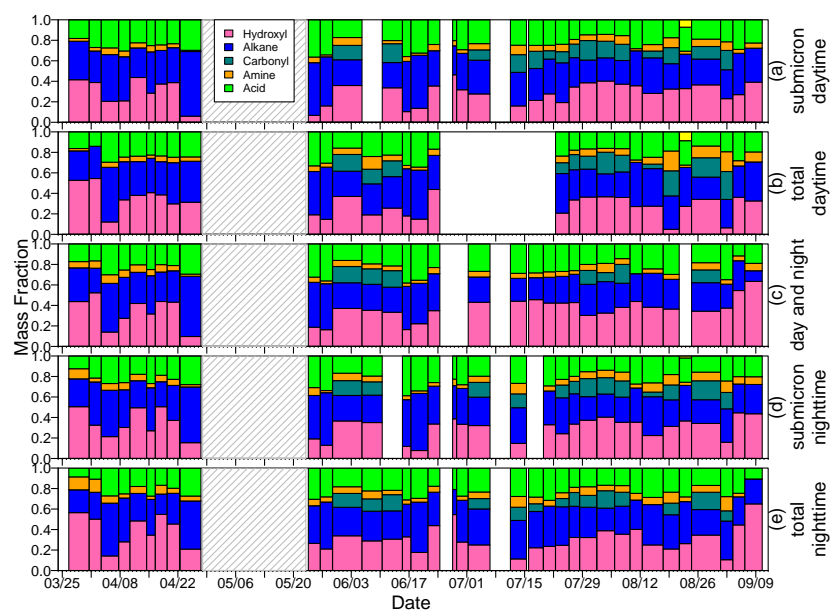

Fig. 2. Time series of OFG fraction as stacked bars with colors as in Fig. 1 (organic hydroxyl (pink), alkane (blue), ketone (teal), primary amine (orange), acid (green), organosulphate (yellow)) in (a) day submicron, (b) day total, (c) day and night (submicron before 29 May 2009, and total post that date), (d) night submicron and, (e) night total aerosol for OM above detection limit samples.

submicron and total samples together, are $3.1 \pm 3.2 \mu \mathrm{g} \mathrm{m}^{-3}$, $3.3 \pm 3.2 \mu \mathrm{g} \mathrm{m}^{-3}$, and $3.2 \pm 3.3 \mu \mathrm{g} \mathrm{m}^{-3}$, respectively. The mean $\mathrm{OM}$ of $4.1 \pm 3.5 \mu \mathrm{g} \mathrm{m}^{-3}$ during the summer period (from late May to Sept) is significantly higher than the $0.6 \pm 0.3 \mu \mathrm{g} \mathrm{m}^{-3}$ mean concentration measured during the first month, corresponding to the spring season. This difference in the periods is emphasized by a comparison of the maximum concentrations of $1.2 \mu \mathrm{g} \mathrm{m}^{-3}$ and $13.6 \mu \mathrm{g} \mathrm{m}^{-3}$ during the spring and summer periods, respectively. The episodic variations in OM concentrations quantified by FTIR are also captured by co-located organic aerosol measurements from the ACSM, with a correlation coefficient of 0.88 and reduced major axis regression slope of 0.57 between the two methods. A time-dependent collection efficiency was estimated for the ACSM, using its ammonium to sulphate ratio (as described by Quinn et al., 2006) with a collection efficiency of 1 for a ratio of zero (sulphuric acid) and 0.45 for a ratio of 1 (ammonium sulphate), with values linearly interpolated in between. This calculated collection efficiency was 0.49 on average; the post-corrected correlation between the ACSM and FTIR OM is 0.88 with a new major axis regression slope of 1.25. The independent correction brings the ACSM-FTIR in agreement within $25 \%$ on average, but with a strong correlation, which is more relevant for the analysis in trends considered in this manuscript.

The OFG composition as OM fraction is shown in Fig. 2. On average, organic hydroxyl, alkane, carboxylic acid, ketone, and primary amine groups represented $31 \% \pm 11 \%$, $34 \% \pm 9 \%, 23 \% \pm 6 \%, 6 \% \pm 7 \%$, and $6 \% \pm 3 \%$ of OM, respectively. Organosulphate groups were above detection limit for only three samples collected during one sampling 

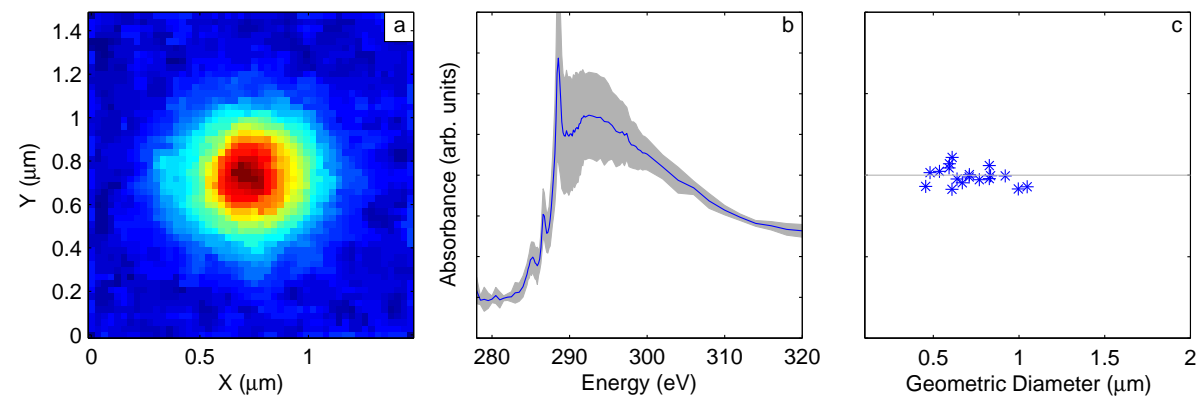

Fig. 3. Images, spectra, and sizes from STXM-NEXAFS analysis. (a) Representative absorbance image at 288 electron volts (eV) for particles with absorption at ketone band $(286.7 \mathrm{eV})$. All 18 particles of this type were spherical. (b) Average spectra (blue lines) \pm one standard deviations (grey regions). (c) One-dimensional plot showing size and number of particles in used to calculate average and standard deviation of absorbance spectrum (points are randomly jittered along y-axis to minimize overlapping of symbols).

period (marked in Fig. 1) and represented 2 to $9 \%$ of OM when present. Two periods during which total OM was significantly larger than submicron OM are marked by a red bar in Fig. 1 and will be discussed further in Sect. 3.2. Acid group fraction and alkane group fraction are strongly correlated to each other $(r=0.82 ; n=65)$ and moderately anticorrelated to organic hydroxyl group fraction $(r=-0.74$; $n=65$ ). Ketone groups were observed in the summer period only. In samples during the summer period that had ketone groups above detection limit, ketone groups composed up to $27 \%$ of OM with an average of $14 \%$ of OM, indicating significant differences in environmental conditions favoring ketone group formation as observed at the Whistler Peak site. In this study, the relative contribution of ketone groups to the total OM mass was mildly to strongly correlated with BC number concentrations $(r=0.79 ; n=30)$, total submicron particle number concentrations $(r=0.7 ; n=28)$, dust ( $r=0.56$ to $0.75 ; n=64)$, and $\mathrm{Br}(r=0.75 ; n=64)$, more than any other OFG. Ketone absorption was also observed in 18 out of 30 individual particles (Fig. 3) imaged by STXM-NEXAFS on 1 and 21 August, and the overall absorption spectra and spherical shapes indicate that these particles are amorphous carbon tarballs produced during BB events (which exhibit ketone absorption) (Tivanski et al., 2007). The rest of the NEXAFS spectra did not have distinct signatures of functional group absorption (more observation of these nondescript particles are discussed by Takahama et al., 2007). Schwartz et al. (2010) attributed the presence of ketones at the Whistler mid-valley site to biogenic (forest) emissions; Hawkins and Russell (2010) hypothesize that the abundance of ketones observed at the Scripps pier may have also originated from forest BVOCs co-emitted during burning events. Oxidation products of non-aromatic ring structures (e.g., pinonaldehyde, pina ketone from monoterpenes) are known to contain ketones (as summarized in Table 2 by Schwartz et al., 2010). Influences from both burning and non-burning terrestrial vegetation were observed more frequently during the summer period (Sect. 3.3.2), coinci- dent with the observation of ketone groups associated with these source emissions or products.

\subsection{Size and diurnal comparison}

The comparisons between the submicron and total OM and OFGs for both day and night are shown in Fig. 4. In all but a few samples, the total and submicron OM measurements compare very well and within the uncertainties of the measurements. The average total to submicron OM ratio is 0.99 with a correlation coefficient equal to 0.97 . Total and submicron $\mathrm{OM}$ are indistinguishable during most samples, suggesting that little organic mass is present in supermicron particles. This is in contrast with element concentrations analyzed by XRF on the same filters. For elements typically associated with dust emissions ( $\mathrm{Ti}, \mathrm{Fe}, \mathrm{Ca}, \mathrm{K}, \mathrm{Si}, \mathrm{Al}, \mathrm{Sr}$, $\mathrm{Mn}$ ), their mass concentrations in submicron aerosol were $47-67 \%$ of that measured in the total samples ( $\mathrm{Si}$ and $\mathrm{Ca}$ shown in Fig. 4); this fraction was consistent for each element (correlation coefficients between these submicron and total aerosol concentrations were $>0.95$ ).

During two periods, 17 to 21 August (night only) and 24 August to 31 August, a large difference between total and submicron $\mathrm{OM}$ measurements was observed, indicating $\mathrm{OM}$ was present in supermicron particles. Supermicron and submicron OFG composition is similar in all but the 17 to 21 August night samples. A discussion of possible source influences during this period is discussed in Sect. 3.3.2.

Significant systematic differences between day and night samples were not observed in FTIR-quantified mass concentrations of $\mathrm{OM}$ and OFGs (Fig. 5). Diurnal variations are observed in concentrations of elements associated with dust emissions, however, with higher loadings observed during the day (night-time concentrations ranged between 43 and $86 \%$ of day-time concentrations and showed relatively consistent trends for each elements; examples for $\mathrm{Si}$ and $\mathrm{Ca}$ shown in Fig. 5). Observation of a systematic difference in dust concentrations indicates that diurnal variations in locally-emitted aerosols, presumably reflecting changes in 

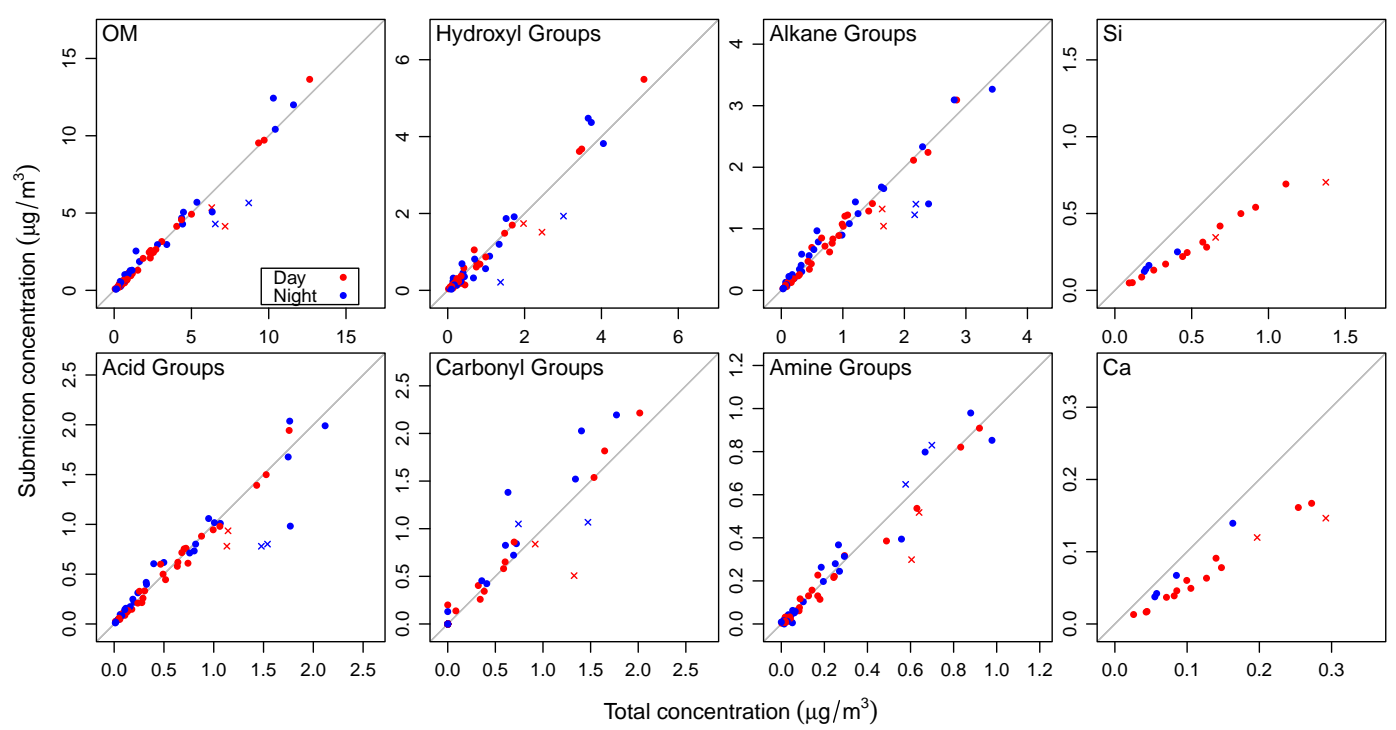

Fig. 4. Comparison between total and submicron sample types for OM, OFGs, and two crustal elements for both day (red) and night (blue) samples. $\times$ 's mark samples with detectable supermicron organic aerosol.
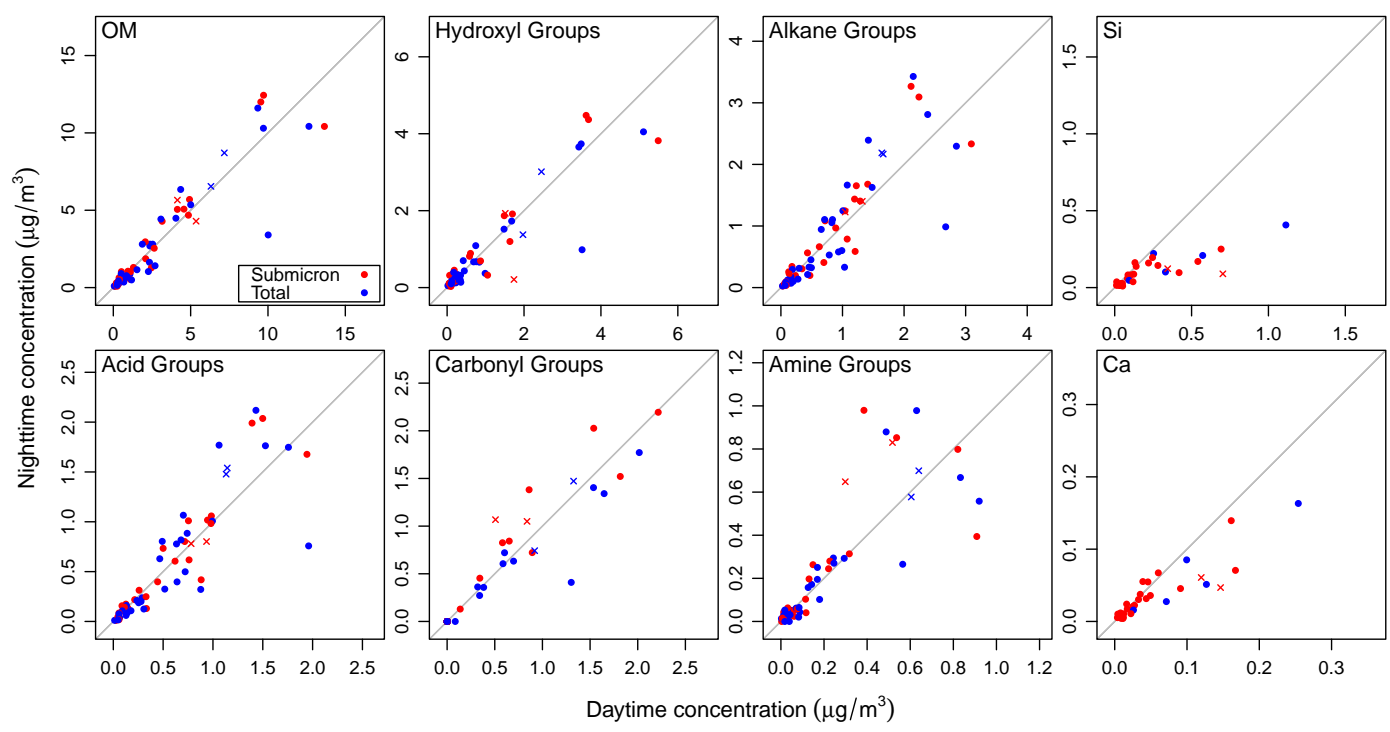

Fig. 5. Comparison between day (06:30 PST to 18:30 PST) and night sample types for OM, OFGs, and two crustal elements for both submicron (red) and total (blue) samples.

the boundary layer height, were detected at the Whistler Peak site. The lack of large and systematic differences in OM suggests that on average, the measured organic aerosol originates from a regional rather than immediately local source, as temporal variation in source signatures is expected to be lost in aged air masses. Non-local organic aerosol sources are consistent with previous studies at the Whistler Peak location and are expected for this high-altitude, remote measurement site (Sun et al., 2009; Leaitch et al., 2009); this will again be discussed in Sect. 3.3.2.

\subsection{Organic aerosol sources impacting the site}

Schwartz et al. (2010) identified anthropogenic combustion and biogenic, or non-burning forest, sources during measurements in the spring of 2008 at the Whistler mid-valley site. Here we consider these sources with the addition of BB which was prominent in the region for much of the summer. The British Columbia 2009 wildfire season was exceptionally severe in its length, number of fires, and area burned, and was accompanied by low precipitation. According to the British Columbia Wildfire Management branch, the 2009 fire 


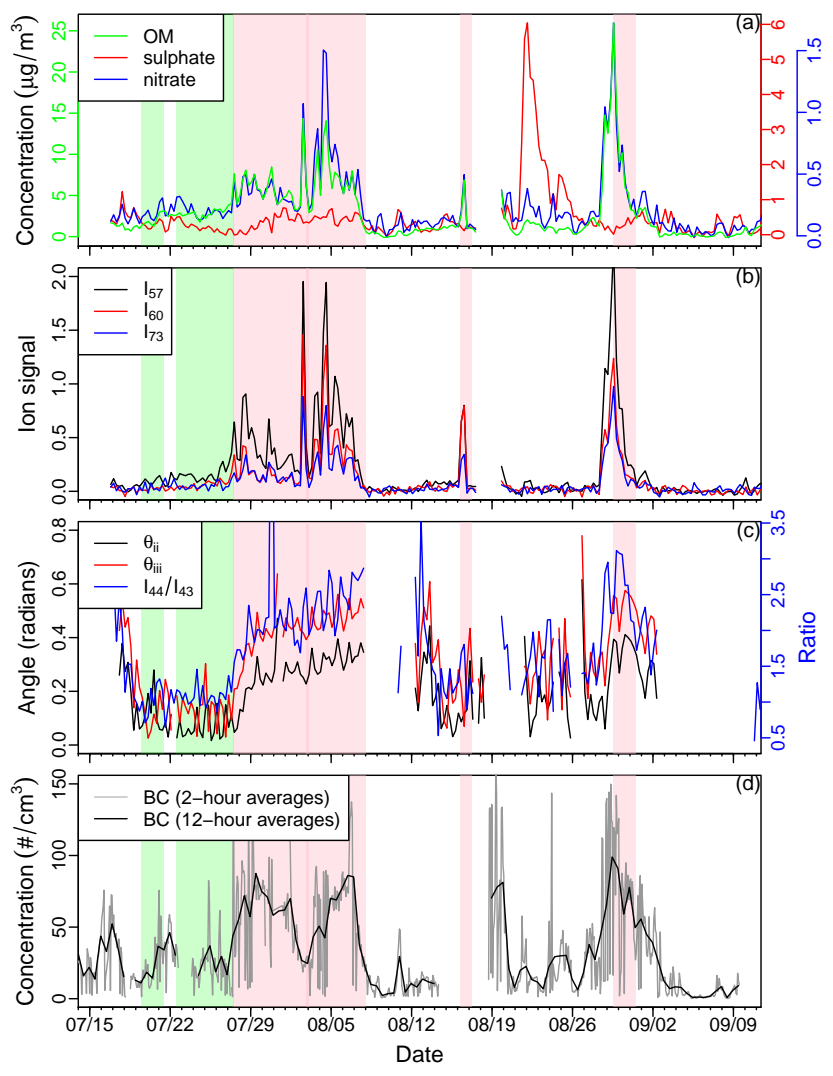

Fig. 6. Time series of co-located measurements of (a) ACSM OM, $\mathrm{SO}_{4}$, and $\mathrm{NO}_{3}$ mass concentrations, (b) ACSM ion signals of $\mathrm{m} / \mathrm{z}$ 57, 60, and 73 mass fragments, (c) cosine angle distance of ACSM mass spectra to laboratory spectra from Shilling et al. (2009) and ratio of ion signals of $\mathrm{m} / \mathrm{z}, 44$ to $\mathrm{m} / \mathrm{z}, 43$, and (d) BC number concentrations measured by the SP2. Periods during which ACSM OM is below detection limit is removed from panel (c). Pink indicates periods with biomass burning influence, green indicates periods with primarily non-burning biogenic influence, and no colour indicates periods with other (primarily anthropogenic combustion) influence, as selected by criteria defined in the text.

season had one of the highest number of fires on record, with a total of 3,040 fires (http://bcwildfire.ca/History/Summary. $\mathrm{htm})$. During several time periods in the 2009 campaign, smoke was visible at the sampling site. Two separate fires occurred on Blackcomb mountain (less than $20 \mathrm{~km}$ from Whistler Peak) during 30 July to 8 August. As shown in Fig. 1, the largest OM concentrations measured by FTIR occurred for three samples collected between 28 July to $8 \mathrm{Au}$ gust, with reported concentrations of $10-14 \mu \mathrm{g} \mathrm{m}^{-3}$. McKendry et al. (2010) also identified and studied another fire period between 29 August and 31 August using ceilometer and other measurements. We identify the contributions from these sources (anthropogenic combustion, biogenic, and BB) using differences in perceived chemical and physical characteristics of the measured aerosol and components resolved by high time-resolution measurements, with additional in-

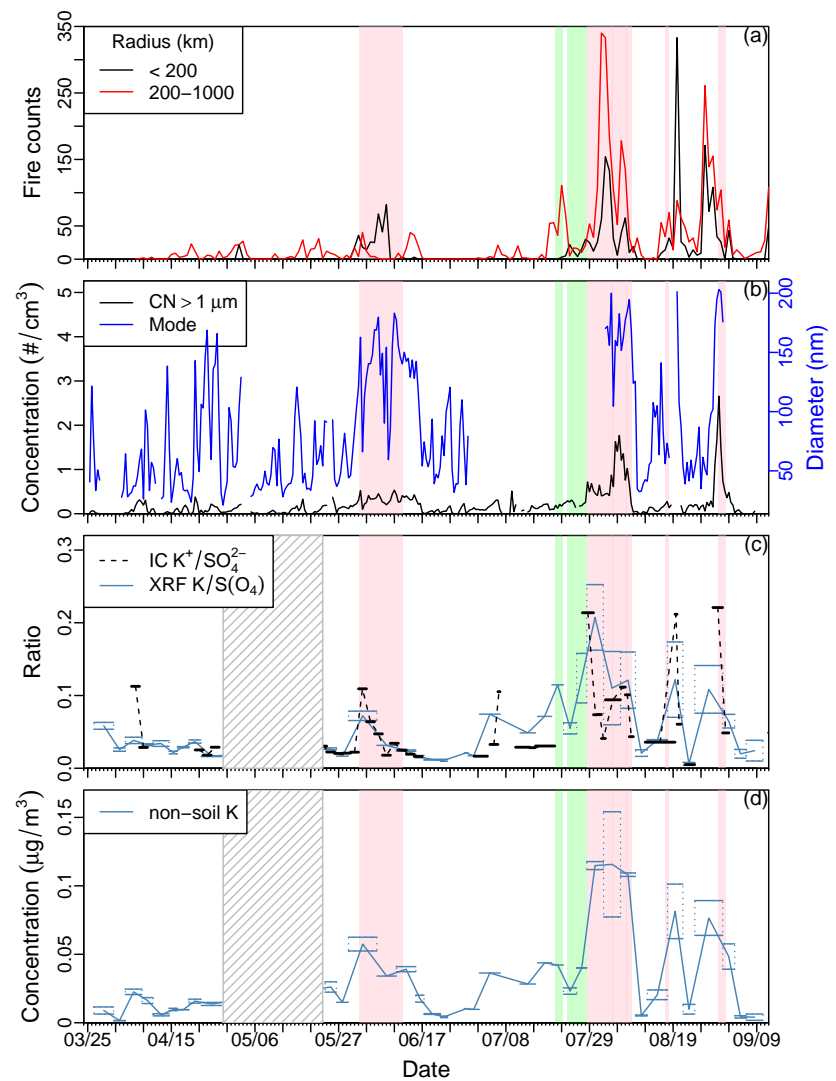

Fig. 7. Time series of (a) fire counts, (b) supermicron number concentrations and mode of full number size distributions (c) potassium to sulphate or equivalent sulphate (all sulphur assumed to be sulphate) ratios measured by IC and XRF, and (d) non-soil K calculated from XRF measurements. Boxes for XRF measurements enclose concentrations measured during day and night when both samples were analyzed by XRF. Size distribution modes in (b) are from MSP Particle System (prior to 1 July) and TSI SMPS (afterwards). Non-soil $\mathrm{K}$ in (d) is calculated as $K=R_{\text {soil }} A l$, where a value of $R_{\text {soil }}=0.06$ is used (Gilardoni et al., 2009). Panel shading colours indicate same information as Fig. 6.

sight gained from factor and regression analyses on FTIR spectra, and geo-spatial information regarding backtrajectories and fire locations.

\subsubsection{Identifying periods of source dominance}

Periods strongly influenced by burning and non-burning forest emissions are differentiated from those influenced heavily by anthropogenic combustion by examining the relative fraction of organic aerosol to organic and sulphate aerosol from the ACSM (absolute concentrations shown in Fig. 6a). During these forest-emission-dominated periods, this organic fraction is $>70 \%$. Episodes of BB are distinguished from non-burning periods by examining the count of local and regional fire hotspots (Fig. 7a, data provided by Natural Resources Canada, http://www.nrcan-rncan.gc.ca) and 
(a)

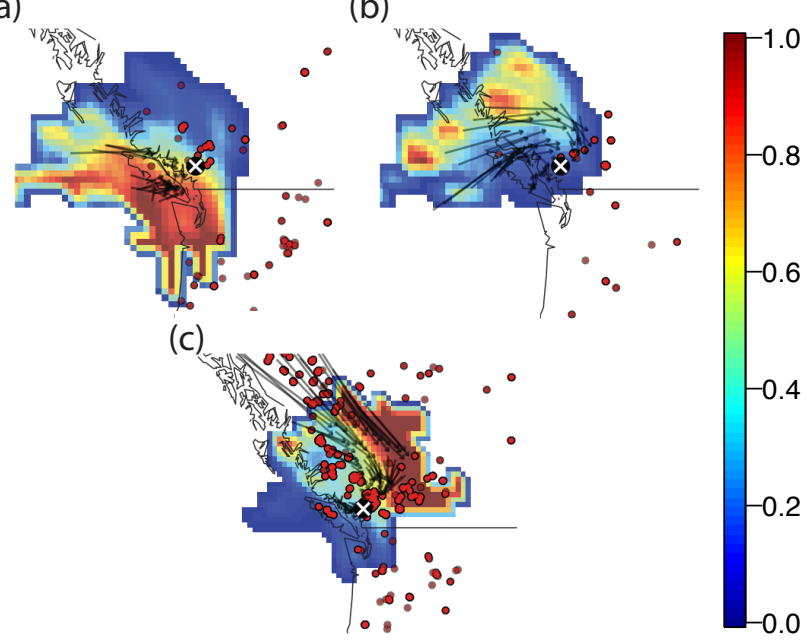

Fig. 8. Potential Source Contribution Function (PSCF) maps shown for (a) periods not corresponding to biogenic or biomass burning events (anthropogenic combustion/other), (b) periods identified as having been impacted primarily by non-burning forest emissions, and (c) periods identified as having been impacted primarily by biomass-burning emissions. Black lines indicate coastline and USCanadian border. Heat map coloring represents the probability of source contribution (blue = low, red=high) at each location, though for remote sources, warmer (red) colors may only indicate general direction of source. Black arrows indicating wind vectors are superposed (from NOAA HYSPLIT backtrajectory simulations). Whistler Peak measurement site is marked by a white $\mathrm{x}$ in each map. Red circles indicate locations of fires by satellite imagery (source: Natural Resources Canada, http://www.nrcan-rncan.gc.ca).

increases in concentrations of mass fragments $\mathrm{m} / \mathrm{z} 57,60$, and 73 (Fig. 6b; Schneider et al., 2006; Lee et al., 2010). The selection of these periods is confirmed by the rise in potassium to sulphate ratio (Fig. 7c) and calculated non-soil potassium concentrations (Fig. 7d), which are measured on a more coarse time resolution by filter-based methods. Lower values of cosine angle metric between ambient mass spectra and laboratory spectra of Shilling et al. (2009) are also observed during periods when the metrics for BB are low or absent. The mass spectra are more similar to the products of $\alpha$-pinene ozonolysis, indicated by the lower values of this angle metric. The increasing ratio of $m / z 44$ to $m / z 43$ fragments indicates the presence of a more oxygenated organic aerosol (Ng et al., 2010) during BB periods compared to periods influenced by non-burning biogenic emissions. During these periods, $\mathrm{BC}$ number concentrations, coarse particle number concentrations, and modes of particle size distributions are also observed to increase, indicating a change in airmass. Though not specific to BB events, an increase in the particle mode diameter has been observed during such periods (e.g., Rissler et al., 2006).

Based on the above criteria, we identify periods or episodes described above in Figs. 6 and 7 as non-burning biogenic (green), BB (pink) and anthropogenic combustion (no colour). Their relationship to relative spatial distributions of backtrajectories and geographical features (cities, forests, and fire hotspots) using PSCF are shown in Fig. 8. The anthropogenic combustion periods are likely to be influenced by regional emissions from Northwest cities such as Vancouver and Seattle and pollutants from long-range transport of Asian emissions (Fig. 8a), consistent with measurements of sulphate at Whistler Peak by Sun et al. (2009). Meteorological trajectories extending back 5 days indicate another set of trajectories with possible origins from Asia, outside of the domain of PSCF analysis. In agreement with the fire count time series shown previously, PSCF maps indicate collectively lower fire counts during non-burning biogenic source periods than biomass-burning periods, and wind trajectories arrive at Whistler Peak from the north over forested regions (Fig. 8b). During BB episodes, airmasses appear to arrive primarily from northeast of the site after passing near or over hotspots during fire periods (Fig. 8c), concurrent with smoke and reduced visibility often reported at the peak site. Figure 8 supports the attribution of periods to emission sources.

\subsubsection{Influence of source on measured organic functional groups}

\section{Spectra categories and source contributions from regression analysis}

To interpret the influence of source on measured OFGs, categories created by the clustering approach described in Sect. 2 are used to discuss the submicron aerosol spectra (Fig. 9). The result is a set of several categories containing spectra with similar features, and the membership of each filter to these categories in time is illustrated in the lower panel of Fig. 9. We interpret the features present in the spectra in the context of FTIR PMF factors derived from previous campaigns (Schwartz et al., 2010; Hawkins and Russell, 2010), and assess relative contributions of these components to each cluster by regression analysis. The results from the regression analysis may be considered qualitative, as they are dependent upon the assumptions regarding (1) components present in each sample and (2) absorption profiles of the components. In addition, some degree of collinearity is present in the spectral profiles combined from the previous campaigns. For instance, the correlation between spectralprofile pairs of anthropogenic combustion and "Biogenic Part 1" from Whistler mid-valley (Schwartz et al., 2010), and "Biogenic Part 3" from Whistler mid-valley (Schwartz et al., 2010) and the Scripps Pier BB factor (Hawkins and Russell, 2010) components are both 0.82 , leading to an inflated variance in contribution estimates. This effect may lead to higher uncertainty in apportioned values between the anthropogenic combustion and forest component, and between the forest and BB components. However, these results provide 

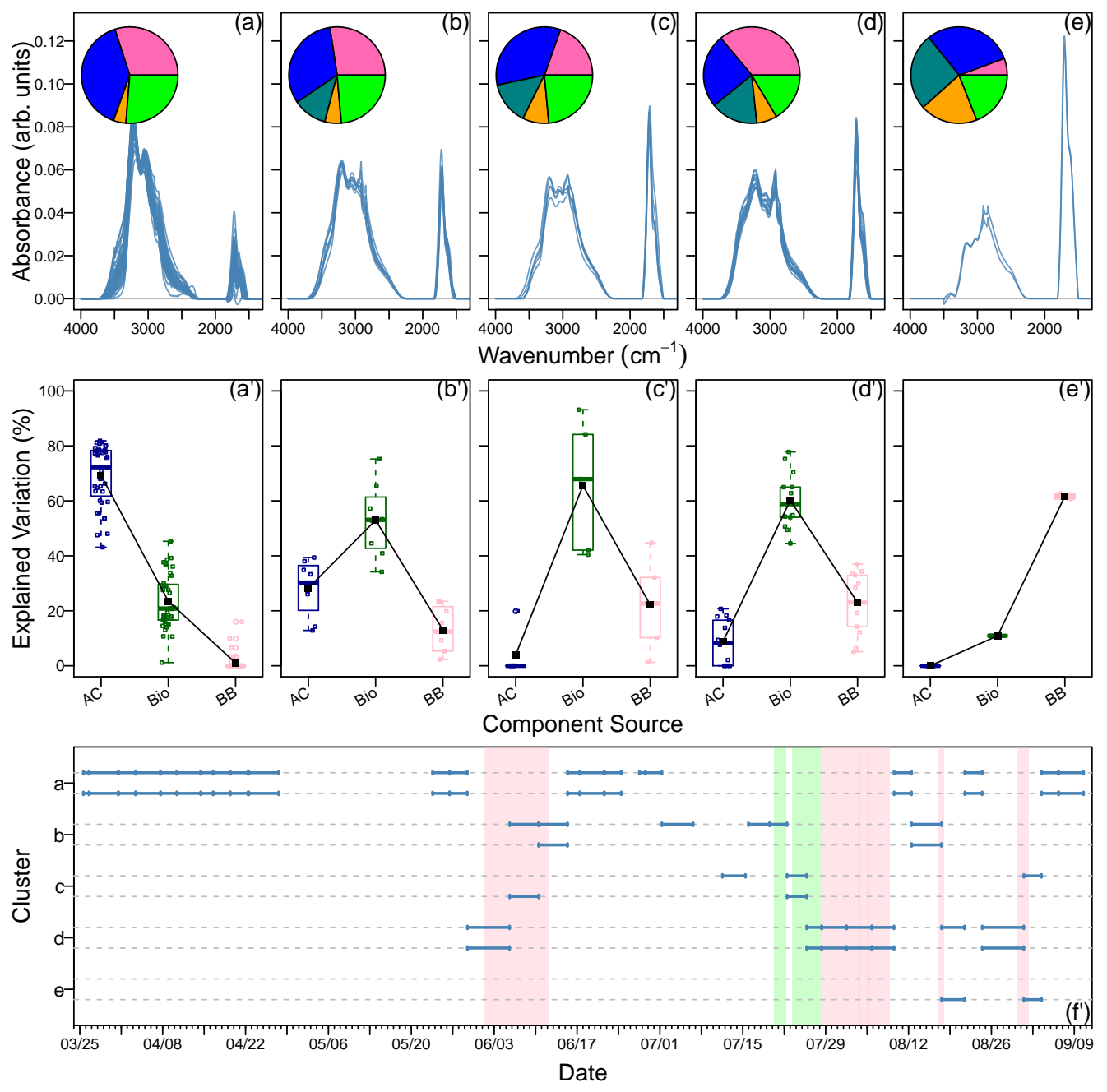

Fig. 9. (a)-(e) Clustered FTIR spectra of submicron aerosol with inset pie graphs depicting average relative contributions of each functional group to OM: hydroxyl (pink), alkane (blue), acid (green), ketones (teal), and primary amine (orange) groups. (a')-(e') Relative contributions (as Explained Variance) from regression analysis for anthropogenic combustion (AC), biogenic (Bio), and biomass burning (BB) components shown as box-and-whisker plots, with individual points overlaid for each category. (f') Time series indicating membership of samples to one of five clusters (labeled on y-axis) introduced in top row. Bars horizontally span sampling periods for each filter; positive and negative vertical offsets indicate day or night samples respectively. Pink indicates periods with biomass burning influence, and green indicates periods with primarily non-burning biogenic influence.

first-order insights into the relative contribution of different source components to each spectra type.

Spectra in category (a) are suggested to have origins in fossil-fuel anthropogenic combustion. Aerosols having this spectra are accompanied by sulphur concentrations twice as high on average (uncorrected value of $0.8 \mu \mathrm{g} \mathrm{m}^{-3}$ ) as during other periods, and FTIR spectral profiles resemble anthropogenic combustion factors identified at the Whistler mid-mountain site and other field campaigns (Russell et al., 2009; Liu et al., 2009; Hawkins and Russell, 2010). This spectra type or component has the characteristic ammonium absorbance that is observed for the anthropogenic combustion factors identified by PMF on FTIR spectra, and its or- ganic fraction contains large fractions of alkane and acid (39 and $26 \%$, respectively, on average), with little contribution from ketonic groups. This category of aerosols appear to contain more organic hydroxyl than anthropogenic combustion factors derived from PMF (hydroxyl mass fraction is on average $30 \%$, contrasted with $17 \%$ at Whistler midvalley, Schwartz et al., 2010). This suggests a mix of anthropogenic combustion with biogenic (Schwartz et al., 2010) or marine sources (Russell et al., 2010), as forests around Whistler or the Pacific Ocean may contribute to the organic aerosol transported to the site from anthropogenic combustion sources. Regression analysis using anthropogenic combustion, forest, and BB sources supports the forest attribution 
of the source of this feature (Fig. 9a'), indicating the largest contributions from anthropogenic combustion ( $70 \%$ on average), with smaller contributions (24\% on average) from forest components. As the Whistler Peak is surrounded by forest sources, it is not surprising to find forest contributions to all samples. Aerosols with spectra belonging in this cluster were collected during periods not designated as non-burning biogenic or burning periods, suggesting that indeed the primary source of influence is likely to be anthropogenic combustion.

Spectra in category (c) resembles the combined (nonburning) biogenic factor from the 2008 campaign at Whistler mid-valley (Schwartz et al., 2010; Fig. 10b). This factor is not dominated by any one functional group, but is distributed as $34 \%$ alkane, $24 \%$ acid, $20 \%$ hydroxyl, and $14 \%$ carbonyl on average. While aerosols with type (c) spectra were collected during several different periods, two spectra in this category were the only ones observed largely within the bounds of the non-burning biogenic periods (between 20 July and 28 July, Fig. 9f'). Regression analysis also supports this interpretation, with strongest contributions from non-burning forest sources (66\%; Fig. 9c').

Spectra in category (e) are characterized by high carbonyl and primary amine absorption (on average, 26 and $19 \%$ of $\mathrm{OM}$, respectively), very little organic hydroxyl (6\% on average), and a pair of sharp peaks at 2920 and $2850 \mathrm{~cm}^{-1}$. The overall spectral shape and composition is unmistakably attributable to burning sources similar to those observed in many locations (including San Diego, CA, and Mexico City, Mexico; Table 1 and Fig. 2D by Russell et al., 2011), and this aerosol type measured by FTIR has been shown to correlate with AMS BB aerosol components (Hawkins and Russell, 2010). The proportion of alcohol, acid, and ketone groups are in general agreement with average compositions for similar measurements of BB aerosol reported previously (Russell et al., 2011). The primary amine fraction is significantly higher than what appears to be a background concentration present during other periods, consistent with other findings of elevated amine concentrations in BB aerosol (e.g., Laskin et al., 2009). Regression analysis also supports this interpretation, with BB contributions explaining $60 \%$ of the variation, with $20 \%$ contribution from forest components (Fig. 9e'). These spectra were observed sometime during the evenings of 17 to 21 August and 31 August to 3 September, which were periods independently determined to be influenced by fire emissions (Fig. 9f').

Significant mass contributions from levoglucosan and other anhydrous sugars have been identified in BB aerosol, with levoglucosan mass contributing between $3-16 \%$ of OM identified by gas chromatography and mass spectrometry (GC-MS), (Fine et al., 2002); $25 \%$ by IC analysis and evolved-gas analysis (EGA) (assuming OM/OC of 1.6, Sullivan et al., 2008). However, levoglucosan or its markers have been reported to degrade in aged BB plumes (Hennigan et al., 2010; Cubison et al., 2011). As much as $80 \%$ degradation of levogucosan has been observed in the laboratory under typical atmospheric oxidation conditions (Hennigan et al., 2011). The OM/OC and O/C ratios discussed below indicate an aged $\mathrm{BB}$ aerosol, which is consistent with the low hydroxyl organic aerosol fraction reported here. In addition, FTIR resolves most of the OM mass (Turpin et al., 2000; Russell, 2003), possibly providing a more complete picture of relative composition. The FTIR method is sensitive to the organic hydroxyl content of the aerosol (as demonstrated by Russell et al., 2010), but also measures the alkane groups present in levoglucosan and other anhydrous sugars, in addition to hydrocarbon chains including alkanoic acids, alkanals, waxes. There may also be a non-negligible contribution from burning and non-burning leaf-related emissions. For instance, levoglucosan levels in leaves tend to be lower than wood burning (Schmidl et al., 2008; Sullivan et al., 2008), and concentrations of other anhydrosugars formed during pyrolysis of cellulose can vary across fuel type (Schmidl et al., 2008). Lofted plant waxes co-emitted with biomass burning in forests may also provide a partial explanation for this discrepancy, as evidenced by the visible methylene peaks in the spectra.

This pair of sharp peaks has been observed and described by Hawkins and Russell (2010). The authors observed this same spectral feature in a subset of samples collected at the Scripps Pier during summer 2008, and identified it as being associated with the BB PMF factor (Fig. 10e). The sharpness of the peaks, which are located at the $\mathrm{sp}^{3} \mathrm{C}-\mathrm{H}$ stretching absorption from methylene groups, is suggested to originate from repeating methylene units in long-chain plant cuticle wax detritus (Hawkins and Russell, 2010). Hawkins and Russell (2010) report several observations in which these compounds were lofted in large wildfires (Simoneit, 1985; Fang et al., 1999; Simoneit et al., 2004; Medeiros et al., 2006).

Spectra in categories (b) and (d) (Fig. 9b and d, respectively) appear to contain a mix of sources, more than the other three categories, and their occurrence in time indicates that their collection times span more than one source period (Fig. 9f'). Spectra type (b) appears to have a peak at $3100 \mathrm{~cm}^{-1}$ (as does type a), suggesting the presence of ammonium, but also contains methylene peaks, hydroxyl, and carbonyl; this is possibly a mix of anthropogenic combustion, non-burning biogenic, and BB aerosol. Spectra type (d) shows a strong hydroxyl signature with methylene peaks and carbonyl absorption, and occurs primarily during nonburning biogenic and BB periods. Similarity to a combined forest (burning and non-burning) PMF factor (2-factor solution, discussed below) for this spectra set, suggests that this is a plausible interpretation. Given the remote location of the Whistler Peak sampling site and three to five-day collection times, the occurrence of such a mixture would not be surprising. Relative contributions in each mixture is supported by regression analysis; with variations explained by anthropogenic combustion, non-burning forest, and $\mathrm{BB}$ with on the order of 28,53 , and $13 \%$ for spectra category (b), and 9, 60, 


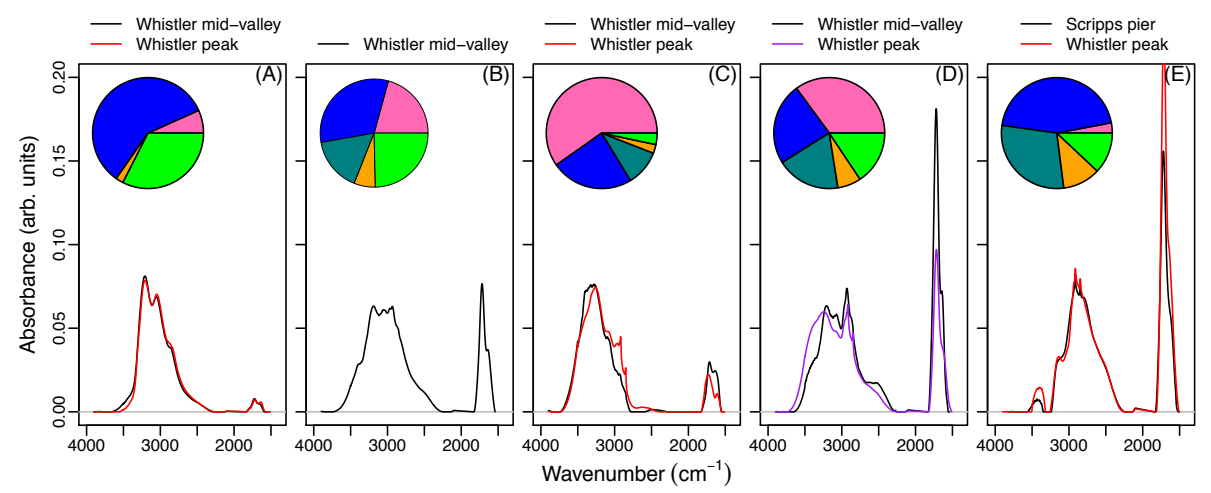

Fig. 10. PMF factors of FTIR spectra from Whistler peak and other studies, with pie graphs showing OFG composition using the color scheme in Fig. 9. (A) Anthropogenic combustion factors from Whistler mid-valley (black; Schwartz et al., 2010) and Whistler peak 3factor solution (red; nearly identical to 2-factor solution). (B) (non-burning) combined biogenic factor from Whistler mid-valley study. (C) Biogenic Factor Part 1 from Whistler mid-valley study (black), and Whistler peak Factor Bio (red). (D) Biogenic Factor Part 2 from Whistler mid-valley study (black), and Whistler peak forest factor from 2-factor solution (purple). (E) biomass burning factor from Scripps Pier study (black; Hawkins and Russell, 2010) in San Diego, CA, and Factor BB from Whistler peak study (red).

and $23 \%$ for category (d), respectively (Figs. $9 b^{\prime}$ and $d^{\prime}$ ). The methylene peaks in these sample spectra indicate the presence of vegetative detritus but may not entirely be attributed to the contribution of BB aerosols in these mixtures; similar compounds may also be emitted from non-burning forest sources, especially in windy regions. Aerosol spectra from Whistler mid-valley in 2008 (as shown in a biogenic factor component in Fig. 10d) - where contributions from wildfire burning were estimated to be minimal - also contain methylene peaks, and their co-occurence with dust (Schwartz et al., 2010) suggests the lofting of detritus even in the absence of fires.

\section{Mass and molar ratios}

The average values of (OM/OC mass, $\mathrm{O} / \mathrm{C}$ atomic) ratios of (2.0, 0.60), (2.0, 0.65), (2.0, 0.57), (2.2, 0.76) and (1.85, 0.45 ) for categories (a) through (e), respectively, and in general agreement with aged aerosol previously measured by AMS by Sun et al. (2009) at Whistler Peak for one month during April and May 2006. The lower OM/OC and O/C ratios for BB aerosol (relative to oxygenated aerosol) is also consistent with values reported by Aiken et al. (2008) for BBOA aerosol measured by the AMS in Mexico City, though the ratios at Whistler Peak are closer to those measured by aircraft above Mexico City than at the ground site. This may indicate that the BB aerosol measured at Whistler Peak is also aged, consistent with finding a smaller fraction of hydroxyl groups in the OM mass than would be expected for fresh $\mathrm{BB}$ aerosol. The OM/OC mass ratios for all aerosol types measured at the Whistler Peak samples, even for the samples primarily derived from anthropogenic combustion, are generally higher than measured for urban areas (Russell, 2003; Aiken et al., 2008). Aerosol aging can also lead to a high rate of functionalisation (Robinson et al., 2007). The high fraction of organic acid and ketone groups in BB and aerosol from non-burning forest sources suggest that a large portion of the aged aerosol observed at the Whistler Peak site may be secondary, as also suggested by Sun et al. (2009) and Schwartz et al. (2010).

\section{Component profiles and source contributions inferred PMF analysis}

PMF analysis was also applied to the FTIR spectra for submicron aerosols to determine if the mixed aerosol types can be resolved into constituent profiles and contributions. In two- to six-factor PMF decompositions, one factor (Fig. 10a) sharing spectroscopic characteristics of the anthropogenic combustion cluster (Fig. 9a) consistently appears with little change in profile or strength among rotations and number of factors, while the remaining variance is divided among the other factor(s). The three-factor solution will be discussed primarily as its factors represent physically plausible spectra that adequately reproduce the sample spectra (details on solution-selection criteria are further discussed by Russell et al., 2009, and Russell et al., 2011).

This solution explained $90 \%$ of the variance in the spectra, on average. In this solution, one of the two remaining factors closely resembles the BB component spectra reported by Hawkins and Russell (2010), as seen in Fig. 10e, and for this reason it is referred to as Factor BB. The Factor BB spectra contains the sharp methylene double peaks noted earlier, and relatively high absorbance by ketone groups. A large fractional contribution of ketone has not been observed in anthropogenic combustion or marine FTIR PMF components, but has been observed in both BB and biogenic sources (Hawkins and Russell, 2010; Schwartz et al., 2010; Bahadur et al., 2010). Hawkins and Russell (2010) also observed a significant fraction of ketone in their $\mathrm{BB}$ fraction at the 


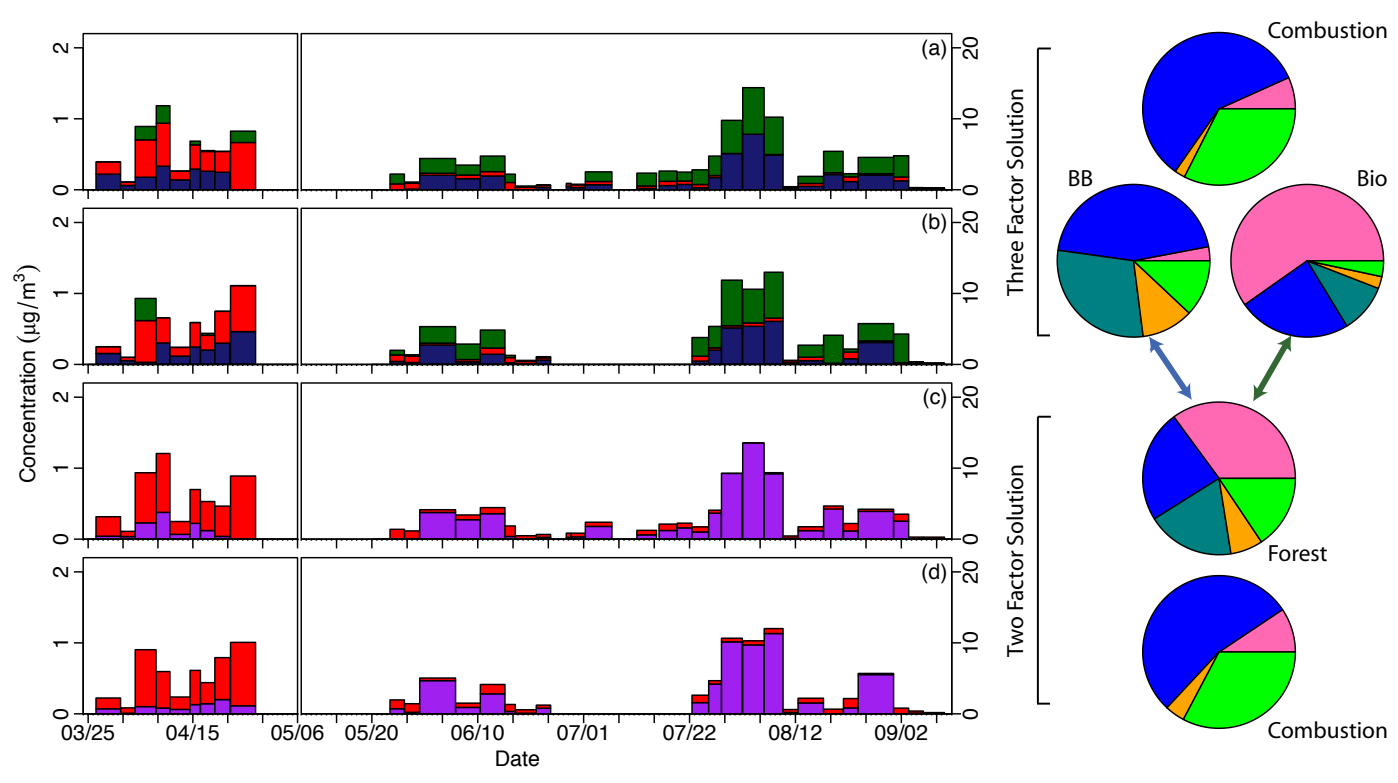

Fig. 11. Time series of submicron OM reconstructed from (a) day samples and (b) night samples for three-factor PMF with anthropogenic combustion factor (red), Factor Bio (dark green), and Factor BB (blue). Two-factor PMF solution is shown for (c) day samples and (d) night samples with anthropogenic combustion factor (red) and forest factor (purple). Note the different axis scale for the spring and summer periods. In the right panel, the OFG composition of the factors are represented with organic hydroxyl (pink), alkane (blue), ketone (teal), primary amine (orange), and acid (green) groups. Factor BB (left pie) and Factor Bio (right pie) from the three-factor solution are essentially a split of the forest factor from the two-factor solution.

Scripps Pier. The ketone fraction of Factor BB is similar to that reported by Hawkins and Russell (2010) (25\%). Factor $\mathrm{BB}$ is correlated to $\mathrm{Br}(r=0.67)$ and non-soil $\mathrm{K}(r=0.69)$, which are considered to be tracers for BB (Andreae et al., 1996 and Gilardoni et al., 2009, respectively). The spectral profile of Factor BB also resembles the spectral cluster shown in Fig. 9e (corresponding to sampling periods 17 to 21 August and 31 August to 3 September). The number of samples in this category is small, but appears to be an "edge" case in the search space of PMF. Edge cases represent events in which one or few sources dominate mixture proportions, providing better constraints on component identities (Henry, 2003).

The spectral profile of the remaining factor resembles nonburning forest emissions and is referred to as Factor Bio. The Factor Bio spectrum resembles the high-hydroxyl "Biogenic Part 1" identified from the mid-mountain Whistler measurements of Schwartz et al. (2010) (Fig. 10c). Biogenic Part 1 was correlated to monoterpenes and dust. Factor Bio has a ketone contribution unlike Biogenic Part 1, but similar to the combined Whistler 2008 biogenic factor (Fig. 10b). The presence of ketone is consistent with the initial products of BVOC oxidation, as suggested by laboratory chamber studies of monoterpene and isoprene oxidation products (Table 2 of Schwartz et al., 2010) and measurements of ambient aerosol influenced by forest sources (Bahadur et al., 2010). Ketones were not observed in the total, continuous samples during non-burning forest aerosol periods (Fig. 2), while it was observed in the submicron and total samples when for day or night-only samples. The carbonyl absorption for the total, continuous periods were not below detection limit, but (unambiguously) apportioned to carboxylic acid rather than ketones according to the algorithm described in Russell et al. (2009). The methylene peaks also appear in Factor Bio, which is a reasonable outcome if long-chain plant waxes are lofted by the wind from non-burning forest sources.

While the anthropogenic combustion factor is highly prominent in the low OM period in March and April, the two forest (burning and non-burning) sources are the main contributors to the high OM during May to September (Fig. 11ab), a period characterized by higher temperatures and numerous sporadic fires. The contribution of Factor Bio to the spring season when there were no fires is higher relative to Factor BB. It is worth noting, however, that Factor BB and Factor Bio spectral profiles have an apparent correlation coefficient of 0.88 . As discussed previously, multi-collinearity is a well-known issue in regression problems, and its presence indicates that the variance in estimated strengths of our components are likely to be inflated. Observations suggest that this is the case for Factor Bio and Factor BB. During the large local fire period of 30 July to 8 August the relative contribution of Factor Bio increases rather than Factor BB. Factor BB, in small contributions, is observed during time periods of no to little wildfires such as the spring and early July. For these periods, it is likely that the magnitude of component strengths cannot be differentiated from each 
other in the former case, or from zero in the latter example. Also, in the case of PMF analysis where component strengths and profiles are both estimated from the data, it is possible that errors in the estimated coefficients (strengths) may also lead to errors in the factor profiles. The close resemblance of factor profiles for the Whistler Peak site to profiles derived for other campaigns and independently attributed to probable sources (e.g., Hawkins and Russell, 2010 and Schwartz et al., 2010) suggests that the error in overall shape of our profiles is small.

Exploring other possible solutions, we find that the fourfactor solutions retains the anthropogenic combustion factor but further splits Factor BB into component profiles previously unobserved in ambient and laboratory spectra, and this pattern is repeated out to the six-factor decomposition. As Ulbrich et al. (2009) point out, components can be arbitrarily "split" into artificial factors once the prescribed number of factors exceeds the number of resolvable components, which may be a possible interpretation in this case. The twofactor solution contains the anthropogenic combustion factor and a factor combining the features of the burning and nonburning forest factors (methylene peaks and high carbonyl absorbance) as shown in Fig. 10d. This solution explained $80 \%$ of the variation on average, but the explained variation was approximately $30 \%$ for type (e) samples (BB) and was as low as $62-64 \%$ for some samples in cluster (c) (nonburning biogenic), suggesting that this forest factor does not represent the extreme cases of burning and non-burning products well. The similarity of the two anthropogenic combustion factors both in composition and in temporal contribution to OM over the whole campaign as shown in Fig. 11 is noteworthy. This robustness in the anthropogenic combustion factor profile and strength suggests that anthropogenic combustion is a chemically consistent source of organic aerosol to Whistler Peak.

The spectral profiles derived from PMF correspond to the average profiles of components contributing to Eulerian measurements at a fixed location (e.g., Whistler Peak). When relating possibly non-conservative components to source profiles, we implicitly invoke the assumption of quasistationarity (Zhou et al., 2005). If chemical transformations are occurring during transport (and are reflected in the observed spectra at the site), the transformations must be relatively consistent for each of the PMF components such that each component represents the contributions from the primary emission signature and a (semi-)constant transformation term. When rates of transport dominate over transformation mechanisms across arbitrary distances for aerosols with regional sources, instances of homogeneous composition over space and time can be observed. The similarity of the anthropogenic combustion and forest PMF factors from this study to those derived for the Whistler mid-valley campaign suggests that the organic aerosols are probably nonlocal to either of these locations, and may be the product of common sources and chemical transformations. The absence of significant day-night differences in $\mathrm{OM}$ observed in this study (Fig. 5) is consistent with the observation that the OM was not dominated by local-scale sources (e.g., daytime photochemistry), and is also consistent with a long-range transported anthropogenic combustion source or forest burning sources (either local or regional). Even a non-burning forest source such as BVOC oxidation may not exhibit a diurnal signal in the $\mathrm{OM}$ as the incremental changes during daytime due to changes in oxidant or BVOC concentrations, and transport time from valley to the Peak may not permit sufficient distinction relative to the existing aerosol, particularly with 12-h integrated filters. The spectral similarity in the BB factor at Whistler Peak and Scripps Pier is surprising, given the possible differences in atmospheric processing that may occur during transport from fire locations in Western Canada or Northern California to their respective measurement sites. This resemblance may reflect the similarity in chemical composition of organic aerosols emitted from BB sources, but may also reflect the similarity in the chemistry occurring in BB plumes (e.g., VOCs released during burning might be reduced to similar dominant compounds).

\subsubsection{Long-range transport}

The 21 to 24 August three-day sample was the only period for which organosulphate groups were above detection limit. This period also corresponds to the highest sulphate concentrations measured by ACSM (6-h averaged concentrations (uncorrected for collection efficiency) peaking at $6 \mu \mathrm{g} \mathrm{m}^{-3}$ ). The combination of organosulphate groups and supermicron organic particles suggests that air masses sampled from 17 August to 31 August may have been influenced by different sources than those controlling the particle composition during most of the project. On 17 August 2009 the Koryaksky Volcano in Kamchatka, Russia, erupted sending emissions to at least a height of $4000 \mathrm{~m}$ above sea level and causing an air traffic advisory to be issued. Air back-trajectories reach to this general area (Fig. 12), offering the possibility that this increase in sulphur, primarily sulphuric acid, was the result of the transport and oxidation of $\mathrm{SO}_{2}$ from this eruption. However, the general feature of lower organic and higher sulphate mass concentrations is also consistent with the Trans-Pacific transport of Asian pollution to this site (e.g. Leaitch et al., 2009). In either case, a long distance source is a likely explanation.

\subsubsection{Regional sources - mid-mountain and peak comparison}

FTIR measurements of submicron organic aerosol (at approximately 12 -h time resolution) were also collected at Whistler mid-valley 2008 (1020 m a.s.l.) for a month from 16 May to 16 June 2008 (Schwartz et al., 2010). The 2008 submicron $\mathrm{OM}$ at the valley site ranged from less than 0.5 to $3.1 \mu \mathrm{g} \mathrm{m}^{-3}$, with a project mean and standard deviation of 


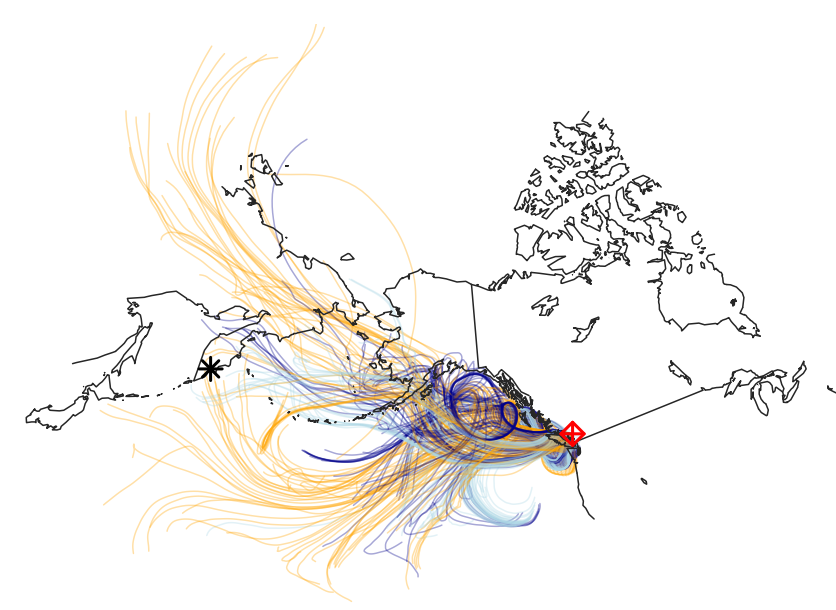

Fig. 12. Seven-day HYSPLIT backtrajectories between 21 to 24 August colored by initial altitude (a.g.1.): $500 \mathrm{~m}=$ dark blue, $1000 \mathrm{~m}=$ light blue, $2000 \mathrm{~m}=$ orange. Red diamond marks Whistler Peak (at 2182 m); black star marks the location of the Kamchatkan volcano Koryasky.

$1.3 \pm 1.0 \mu \mathrm{g} \mathrm{m}^{-3}$. The 2009 measurements from 23 May to 17 June (the most comparable time period to this study) ranged from less than 1.3 to $5.1 \mu \mathrm{g} \mathrm{m}^{-3}$, with a project mean and standard deviation of $3.6 \pm 1.6 \mu \mathrm{g} \mathrm{m}^{-3}$. The average OFG composition of the submicron aerosol was in general similar between the two sites during these periods. Most notably, less organic hydroxyl groups (11\% by mass) were observed in the peak measurements. Despite differences in elevation and surrounding environment (trees surround the 2008 midmountain site, while the Whistler Peak site is above the tree line) factor analysis indicated the the organic aerosol sources influencing the site were nearly identical, with the exception of the BB influence in early June, which is likely to be responsible for the small difference in overall composition and higher OM concentration measured at the site during this period (Schwartz et al., 2010, did not observe a BB influence for the Whistler 2008 study).

\section{Conclusions}

Three-to-five-day ambient OM concentrations measured at Whistler Peak during spring and summer 2009 varied from 0.06 to $13.6 \mu \mathrm{g} \mathrm{m}^{-3}$ with a project mean and standard deviation of $3.2 \pm 3.3 \mu \mathrm{g} \mathrm{m}^{-3}$. Significant systematic trends were not observed in FTIR measurements between day- and nighttime samples. Submicron and total OFG mass concentrations were indistinguishable, with the exception of a few periods. The OM concentrations, which reached $1.2 \mu \mathrm{g} \mathrm{m}^{-3}$ during the spring period from March to April, were consistently lower than the concentrations from May to September. Ketone groups were not detected in the spring but contributed up to $27 \%$ of the average organic aerosol composition in the summer. The OM concentrations measured during spring 2008 in the Whistler mid-valley, at a site over $1 \mathrm{~km}$ lower than the peak location, were lower than the concentrations observed during the corresponding time period at the peak in 2009. The sources identified for the Whistler Peak location were similar to those found at the mid-valley site, with the addition of BB aerosol from the 2009 fire season observed at the Peak site.

From an analysis of aerosol measurements and airmass backtrajectories, the sampling campaign was divided into periods primarily influenced by anthropogenic combustion, non-burning forest emissions, and biomass burning sources. FTIR aerosol spectra resembling the anthropogenic combustion PMF factor from the Whistler mid-valley campaign (2008) were observed during the anthropogenic combustion periods. These spectra have a characteristic ammonium absorbance (often associated with sulphate) and are dominated by alkane functional groups (39\% on average) in the organic aerosol fraction. Spectra of aerosols collected during a few biomass burning periods resembled the biomass burning component from the Scripps Pier campaign (2008) in San Diego, CA. This spectra type contained sharp methylene peaks attributed to plant waxes, and a large contribution of ketones ( $26 \%$ on average) to the organic aerosol mass. Spectra resembling the non-burning biogenic forest component from the Whistler mid-valley campaign were also observed during periods determined to be dominated by non-burning biogenic sources. The remaining FTIR spectra appeared to contain a mixture or aerosols from these three sources, which is a plausible outcome due to the remoteness of the sampling location and three to five-day sampling intervals. While PMF decomposition of this spectra set revealed components (anthropogenic combustion, non-burning biogenic, and burning) similar or nearly identical to factors found in previous campaigns, OM/OC ratios and $\mathrm{O} / \mathrm{C}$ ratios of values often greater than 2.0 and 0.57 , respectively, indicating the organic aerosol observed at the site were highly aged and possibly formed through secondary generation mechanisms.

Acknowledgements. The authors would like to thank Whistler Blackcomb, Juniper Buller, Anton Horvath, and John Shilling for providing the spectra, and Natural Resources Canada (NRCan), as well as John Little for the fire hotspot data. While this study was largely supported by Environment Canada, NSF grant ATM0904203 provided partial support for the participation of S. T., R. S., and L. M. R. The authors also thank the anonymous reviewers for helpful suggestions.

Edited by: M. Ammann 


\section{References}

Aiken, A. C., Decarlo, P. F., Kroll, J. H., Worsnop, D. R., Huffman, J. A., Docherty, K. S., Ulbrich, I. M., Mohr, C., Kimmel, J. R., Sueper, D., Sun, Y., Zhang, Q., Trimborn, A., Northway, M., Ziemann, P. J., Canagaratna, M. R., Onasch, T. B., Alfarra, M. R., Prevot, A. S. H., Dommen, J., Duplissy, J., Metzger, A., Baltensperger, U., and Jimenez, J. L.: O/C and OM/OC ratios of primary, secondary, and ambient organic aerosols with high-resolution time-of-flight aerosol mass spectrometry, Environ. Sci. Technol., 42, 4478-4485, 2008.

Allan, J. D., Delia, A. E., Coe, H., Bower, K. N., Alfarra, M. R., Jimenez, J. L., Middlebrook, A. M., Drewnick, F., Onasch, T. B., Canagaratna, M. R., Jayne, J. T., and Worsnop, D. R.: A generalised method for the extraction of chemically resolved mass spectra from aerodyne aerosol mass spectrometer data, J. Aerosol Sci., 35, 909-922, 2004.

Andreae, M. O., Atlas, E., Harris, G. W., Helas, G., deKock, A., Koppmann, R., Maenhaut, W., Mano, S., Pollock, W. H., Rudolph, J., Scharffe, D., Schebeske, G., and Welling, M.: Methyl halide emissions from savanna fires in southern Africa, J. Geophys. Res.-Atmos., 101, 23603-23613, 1996.

Bahadur, R., Uplinger, T., Russell, L. M., Sive, B. C., Cliff, S. S., Millet, D. B., Goldstein, A., and Bates, T. S.: Phenol Groups in Northeastern US Submicrometer Aerosol Particles Produced from Seawater Sources, Environ. Sci. Technol., 44, 2542-2548, 2010.

Bond, T. C., Streets, D. G., Yarber, K. R., Nelson, S. M., Woo, W. J.-H., and Klimont, Z.: A technology-based global inventory of black and organic carbon emissions from combustion, J. Geophys. Res., 109, D14203, doi:10.1029/2003JD003697, 2004.

Bowman, D. M. J. S., Balch, J. K., Artaxo, P., Bond, W. J., Carlson, J. M., Cochrane, M. A., D’Antonio, C. M., DeFries, R. S., Doyle, J. C., Harrison, S. P., Johnston, F. H., Keeley, J. E., Krawchuk, M. A., Kull, C. A., Marston, J. B., Moritz, M. A., Prentice, I. C., Roos, C. I., Scott, A. C., Swetnam, T. W., van der Werf, G. R., and Pyne, S. J.: Fire in the Earth System, Science, 324, 481-484, 2009.

Canagaratna, M. R., Jayne, J. T., Jimenez, J. L., Allan, J. D., Alfarra, M. R., Zhang, Q., Onasch, T. B., Drewnick, F., Coe, H., Middlebrook, A., Delia, A., Williams, L. R., Trimborn, A. M., Northway, M. J., DeCarlo, P. F., Kolb, C. E., Davidovits, P., and Worsnop, D. R.: Chemical and microphysical characterization of ambient aerosols with the aerodyne aerosol mass spectrometer, Mass Spectrom. Rev., 26, 185-222, 2007.

Chuang, C. C., Penner, J. E., Prospero, J. M., Grant, K. E., Rau, G. H., and Kawamoto, K.: Cloud susceptibility and the first aerosol indirect forcing: Sensitivity to black carbon and aerosol concentrations, J. Geophys. Res.-Atmos., 107, 4564, doi: 10.1029/2000JD000215, 2002.

Cozic, J., Verheggen, B., Weingartner, E., Crosier, J., Bower, K. N., Flynn, M., Coe, H., Henning, S., Steinbacher, M., Henne, S., Collaud Coen, M., Petzold, A., and Baltensperger, U.: Chemical composition of free tropospheric aerosol for PM1 and coarse mode at the high alpine site Jungfraujoch, Atmos. Chem. Phys., 8, 407-423, doi:10.5194/acp-8-407-2008, 2008.

Cross, E. S., Onasch, T. B., Ahern, A., Wrobel, W., Slowik, J. G., Olfert, J., Lack, D. A., Massoli, P., Cappa, C. D., Schwarz, J. P., Spackman, J. R., Fahey, D. W., Sedlacek, A., Trimborn, A., Jayne, J. T., Freedman, A., Williams, L. R., Ng, N. L., Maz- zoleni, C., Dubey, M., Brem, B., Kok, G., Subramanian, R., Freitag, S., Clarke, A., Thornhill, D., Marr, L. C., Kolb, C. E., Worsnop, D. R., and Davidovits, P.: Soot Particle Studies Instrument Inter-Comparison - Project Overview, Aerosol Sci. Technol., 44, 592-611, doi:10.1080/02786826.2010.482113, 2010.

Cubison, M. J., Ortega, A. M., Hayes, P. L., Farmer, D. K., Day, D., Lechner, M. J., Brune, W. H., Apel, E., Diskin, G. S., Fisher, J. A., Fuelberg, H. E., Hecobian, A., Knapp, D. J., Mikoviny, T., Riemer, D., Sachse, G. W., Sessions, W., Weber, R. J., Weinheimer, A. J., Wisthaler, A., and Jimenez, J. L.: Effects of aging on organic aerosol from open biomass burning smoke in aircraft and lab studies, Atmos. Chem. Phys. Discuss., 11, 12103-12140, doi:10.5194/acpd-11-12103-2011, 2011.

Draxler, R. and Rolph, G.: HYSPLIT (HYbrid Single-Particle Lagrangian Integrated Trajectory) Model access via NOAA ARL READY Website on: http://ready.arl.noaa.gov/HYSPLIT.php, 2010.

Fang, M., Zheng, M., Wang, F., To, K., Jaafar, A., and Tong, S.: The solvent-extractable organic compounds in the Indonesia biomass burning aerosols-characterization studies, Atmos. Environ., 33, 783-795, 1999.

Fine, P. M., Cass, G. R., and Simoneit, B. R. T.: Chemical Characterization of Fine Particle Emissions from the Fireplace Combustion of Woods Grown in the Southern United States, Environ. Sci. Technol., 36, 1442-1451, doi:10.1021/es0108988, 2002.

Gilardoni, S., Liu, S., Takahama, S., Russell, L. M., Allan, J. D., Steinbrecher, R., Jimenez, J. L., Carlo, P. F. D., Dunlea, E. J., and Baumgardner, D.: Characterization of organic ambient aerosol during MIRAGE 2006 on three platforms, Atmos. Chem. Phys., 9, 5417-5432, doi:10.5194/acp-9-5417-2009, 2009.

Hallquist, M., Wenger, J. C., Baltensperger, U., Rudich, Y., Simpson, D., Claeys, M., Dommen, J., Donahue, N. M., George, C., Goldstein, A. H., Hamilton, J. F., Herrmann, H., Hoffmann, T., Iinuma, Y., Jang, M., Jenkin, M. E., Jimenez, J. L., KiendlerScharr, A., Maenhaut, W., McFiggans, G., Mentel, T. F., Monod, A., Prevot, A. S. H., Seinfeld, J. H., Surratt, J. D., Szmigielski, R., and Wildt, J.: The formation, properties and impact of secondary organic aerosol: current and emerging issues, Atmos. Chem. Phys., 9, 5155-5236, doi:10.5194/acp-9-5155-2009, 2009.

Hastie, T., Tibshirani, R., and Friedman, J.: The elements of statistical learning: data mining, inference, and prediction, Springer Verlag, Germany, 2009.

Hawkins, L. N. and Russell, L. M.: Oxidation of ketone groups in transported biomass burning aerosol from the 2008 Northern California Lightning Series fires, Atmos. Environ., 44, 41424154, 2010.

Heald, C. L., Jacob, D. J., Park, R. J., Russell, L. M., Huebert, B. J., Seinfeld, J. H., Liao, H., and Weber, R. J.: A large organic aerosol source in the free troposphere missing from current models, Geophys. Res. Lett., 32, L18809, doi:10.1029/2005GL023831, 2005.

Heald, C. L., Jacob, D. J., Turquety, S., Hudman, R. C., Weber, R. J., Sullivan, A. P., Peltier, R. E., Atlas, E. L., de Gouw, J. A., Warneke, C., Holloway, J. S., Neuman, J. A., Flocke, F. M., and Seinfeld, J. H.: Concentrations and sources of organic carbon aerosols in the free troposphere over North America, J. Geophys. Res.-Atmos., 111, D23S47, doi:10.1029/2006JD007705, 2006. 
Hennigan, C. J., Sullivan, A. P., Collett, J. L., and Robinson, A. L.: Levoglucosan stability in biomass burning particles exposed to hydroxyl radicals, Geophys. Res. Lett., 37, 2-5, doi:10.1029/2010GL043088, 2010.

Hennigan, C. J., Miracolo, M. A., Engelhart, G. J., May, A. A., Presto, A. A., Lee, T., Sullivan, A. P., McMeeking, G. R., Coe, H., Wold, C. E., Hao, W.-M., Gilman, J. B., Kuster, W. C., de Gouw, J., Schichtel, B. A., Collett Jr., J. L., Kreidenweis, S. M., and Robinson, A. L.: Chemical and physical transformations of organic aerosol from the photo-oxidation of open biomass burning emissions in an environmental chamber, Atmos. Chem. Phys. Discuss., 11, 11995-12037, doi:10.5194/acpd-1111995-2011, 2011.

Henry, R. C.: Multivariate receptor modeling by N-dimensional edge detection, Chemomtr. Int. Lab. Syst., 65, 179-189, 2003.

Intergovernmental Panel on Climate Change: IPCC: Climate Change 2007: The Physical Science Basis, Contribution of Working Group I to the Fourth Assessment Report of the Intergovernmental Panel on Climate Change, Tech. rep., 2007.

Jayne, J. T., Leard, D. C., Zhang, X. F., Davidovits, P., Smith, K. A., Kolb, C. E., and Worsnop, D. R.: Development of an aerosol mass spectrometer for size and composition analysis of submicron particles, Aerosol Sci. Technol., 33, 49-70, 2000.

Knutson, E. and Whitby, K.: Aerosol classification by electric mobility: apparatus, theory, and applications, Journal of Aerosol Science, 6, 443-451, doi:10.1016/0021-8502(75)90060-9, 1975.

Kulmala, M., Suni, T., Lehtinen, K. E. J., Maso, M. D., Boy, M., Reissell, A., Rannik, U., Aalto, P., Keronen, P., Hakola, H., Back, J. B., Hoffmann, T., Vesala, T., and Hari, P.: A new feedback mechanism linking forests, aerosols, and climate, Atmos. Chem. Phys., 4, 557-562, doi:10.5194/acp-4-557-2004, 2004.

Laskin, A., Smith, J. S., and Laskin, J.: Molecular characterization of nitrogen-containing organic compounds in biomass burning aerosols using high-resolution mass spectrometry., Environ. Sci. Technol., 43, 3764-3771, 2009.

Leaitch, W. R., Macdonald, A. M., Anlauf, K. G., Liu, P. S. K., Toom-Sauntry, D., Li, S. M., Liggio, J., Hayden, K., Wasey, M. A., Russell, L. M., Takahama, S., Liu, S., van Donkelaar, A., Duck, T., Martin, R. V., Zhang, Q., Sun, Y., McKendry, I., Shantz, N. C., and Cubison, M.: Evidence for Asian dust effects from aerosol plume measurements during INTEXB 2006 near Whistler, BC, Atmos. Chem. Phys., 9, 3523-3546, doi:10.5194/acp-9-3523-2009, 2009.

Lee, T., Sullivan, A. P., Mack, L., Jimenez, J. L., Kreidenweis, S. M., Onasch, T. B., Worsnop, D. R., Malm, W., Wold, C. E., Hao, W. M., and Collett, J. L.: Chemical Smoke Marker Emissions During Flaming and Smoldering Phases of Laboratory Open Burning of Wildland Fuels, Aerosol Sci. Technol., 44, I-V, 2010.

Liu, B. Y. H., Romay, F. J., Dick, W. D., Woo, K. S., and Chiruta, M.: A Wide-Range Particle Spectrometer for Aerosol Measurement from $0.010 \mathrm{mu}$ m to $10 \mathrm{mu}$ m, Aerosol Air Qual. Res., 10, 125-139, 2010.

Liu, S., Takahama, S., Russell, L. M., Gilardoni, S., and Baumgardner, D.: Oxygenated organic functional groups and their sources in single and submicron organic particles in MILAGRO 2006 campaign, Atmos. Chem. Phys., 9, 6849-6863, doi:10.5194/acp9-6849-2009, 2009.

Lugauer, M., Baltensperger, U., Furger, M., Gaggeler, H. W., Jost,
D. T., Schwikowski, M., and Wanner, H.: Aerosol transport to the high Alpine sites Jungfraujoch (3454 m asl) and Colle Gnifetti (4452 m asl), Tellus B, 50, 76-92, 1998.

Macdonald, A. M., Anlauf, K. G., Leaitch, W. R., and Liu, P. S. K.: Multi-year chemistry of particles and selected traces gases at the Whistler High Elevation Site, EOS Trans., 87, AEB-0719, 2006.

Maria, S. F., Russell, L. M., Turpin, B. J., Porcja, R. J., Campos, T. L., Weber, R. J., and Huebert, B. J.: Source signatures of carbon monoxide and organic functional groups in Asian Pacific Regional Aerosol Characterization Experiment (ACE-Asia) submicron aerosol types, J. Geophys. Res.-Atmos., 108, 8637, doi:10.1029/2003JD003703, 2003.

McKendry, I. G., Gallagher, J., Campuzano Jost, P., Bertram, A., Strawbridge, K., Leaitch, R., and Macdonald, A. M.: Ground-based remote sensing of an elevated forest fire aerosol layer at Whistler, BC: implications for interpretation of mountaintop chemistry, Atmos. Chem. Phys., 10, 11921-11930, doi:10.5194/acp-10-11921-2010, 2010.

Medeiros, P. M., Conte, M. H., Weber, J. C., and Simoneit, B. R. T.: Sugars as source indicators of biogenic organic carbon in aerosols collected above the Howland Experimental Forest, Maine, Atmos. Environ., 40, 1694-1705, 2006.

Murphy, D. M., Middlebrook, A. M., and Warshawsky, M.: Cluster analysis of data from the Particle Analysis by Laser Mass Spectrometry (PALMS) instrument, Aerosol Sci. Technol., 37, 382-391, 2003.

Ng, N. L., Canagaratna, M. R., Zhang, Q., Jimenez, J. L., Tian, J., Ulbrich, I. M., Kroll, J. H., Docherty, K. S., Chhabra, P. S., Bahreini, R., Murphy, S. M., Seinfeld, J. H., Hildebrandt, L., Donahue, N. M., DeCarlo, P. F., Lanz, V. A., Prevot, A. S. H., Dinar, E., Rudich, Y., and Worsnop, D. R.: Organic aerosol components observed in Northern Hemispheric datasets from Aerosol Mass Spectrometry, Atmos. Chem. Phys., 10, 46254641, doi:10.5194/acp-10-4625-2010, 2010.

Ng, N. L., Herndon, S. C., Trimborn, a., Canagaratna, M. R., Croteau, P. L., Onasch, T. B., Sueper, D., Worsnop, D. R., Zhang, Q., Sun, Y. L., and Jayne, J. T.: An Aerosol Chemical Speciation Monitor (ACSM) for Routine Monitoring of the Composition and Mass Concentrations of Ambient Aerosol, Aerosol Sci. Technol., 45, 770-784, doi:10.1080/02786826.2011.560211, 2011.

Nyeki, S., Baltensperger, U., Colbeck, I., Jost, D., Weingartner, E., and G\\"aggeler, H.: The Jungfraujoch high-alpine research station $(3454 \mathrm{~m})$ as a background clean continental site for the measurement of aerosol parameters, J.Geophys. Res., 103, 60976107, 1998.

Paatero, P.: Users Guide for Positive Matrix Factorization programs PMF2 and PMF3, Part 2: reference, 2007.

Paatero, P. and Tapper, U.: Positive matrix factorization - a nonnegative factor model with optimal utilization of error-estimates of data values, Environmetrics, 5, 111-126, 1994.

Paatero, P., Hopke, P., Song, X., and Ramadan, Z.: Understanding and controlling rotations in factor analytic models, Chemometr. Int. Lab. Syst., 60, 253-264, 2002.

Pekney, N. J., Davidson, C. I., Zhou, L. M., and Hopke, P. K.: Application of PSCF and CPF to PMF-modeled sources of $\mathrm{PM}_{2.5}$ in Pittsburgh, Aerosol Sci. Technol., 40, 952-961, 2006.

Penner, J. E., Zhang, S. Y., and Chuang, C. C.: Soot and smoke aerosol may not warm climate, J. Geophys. Res.-Atmos., 108, 
4657, doi:10.1029/2003JD003409, 2003.

Quinn, P. K., Bates, T. S., Coffman, D., Onasch, T. B., Worsnop, D., Baynard, T., de Gouw, J. A., Goldan, P. D., Kuster, W. C., Williams, E., Roberts, J. M., Lerner, B., Stohl, A., Pettersson, A., and Lovejoy, E. R.: Impacts of sources and aging on submicrometer aerosol properties in the marine boundary layer across the Gulf of Maine, J. Geophys. Res.-Atmos., 111, D23S36, doi:10.1029/2006JD007582, 2006.

Reid, J., Koppmann, R., Eck, T., and Eleuterio, D.: A review of biomass burning emissions part II: intensive physical properties of biomass burning particles, Atmos. Chem. Phys., 5, 799-825, doi:10.5194/acp-5-799-2005, 2005.

Rissler, J., Vestin, A., Swietlicki, E., Fisch, G., Zhou, J., Artaxo, P., and Andreae, M. O.: Size distribution and hygroscopic properties of aerosol particles from dry-season biomass burning in Amazonia, Atmos. Chem. Phys., 6, 471-491, doi:10.5194/acp6-471-2006, 2006.

Robinson, A. L., Donahue, N. M., Shrivastava, M. K., Weitkamp, E. A., Sage, A. M., Grieshop, A. P., Lane, T. E., Pierce, J. R., and Pandis, S. N.: Rethinking organic aerosols: Semivolatile emissions and photochemical aging, Science, 315, 1259-1262, 2007.

Russell, L. M.: Aerosol organic-mass-to-organic-carbon ratio measurements, Environ. Sci. Technol., 37, 2982-2987, 2003.

Russell, L. M., Takahama, S., Liu, S., Hawkins, L. N., Covert, D. S., Quinn, P. K., and Bates, T. S.: Oxygenated fraction and mass of organic aerosol from direct emission and atmospheric processing measured on the R/V Ronald Brown during TEXAQS/GoMACCS 2006, J. Geophys. Res.-Atmos., 114, D00F05, doi:10.1029/2008JD011275, 2009.

Russell, L. M., Hawkins, L. N., Frossard, A. A., Quinn, P. K., and Bates, T. S.: Carbohydrate-like composition of submicron atmospheric particles and their production from ocean bubble bursting, Proc. Natl. Acad. Sci. USA, 107, 6652-6657, 2010.

Russell, L. M., Bahadur, R., and Ziemann, P. J.: Identifying organic aerosol sources by comparing functional group composition in chamber and atmospheric particles, Proc. Natl. Acad. Sci. USA, 108, 3516-3521, 2011.

Schmidl, C., Bauer, H., Dattler, a., Hitzenberger, R., Weissenboeck, G., Marr, I., and Puxbaum, H.: Chemical characterisation of particle emissions from burning leaves, Atmos. Environ., 42, 90709079, doi:10.1016/j.atmosenv.2008.09.010, 2008.

Schneider, J., Weimer, S., Drewnick, F., Borrmann, S., Helas, G., Gwaze, P., Schmid, O., Andreae, M., and Kirchner, U.: Mass spectrometric analysis and aerodynamic properties of various types of combustion-related aerosol particles, Int. J. Mass Spectrom., 258, 37-49, 2006.

Schwartz, R. E., Russell, L. M., Sjostedt, S. J., Vlasenko, A., Slowik, J. G., Abbatt, J. P. D., Macdonald, A. M., Li, S. M., Liggio, J., Toom-Sauntry, D., and Leaitch, W. R.: Biogenic oxidized organic functional groups in aerosol particles from a mountain forest site and their similarities to laboratory chamber products, Atmos. Chem. Phys., 10, 5075-5088, doi:10.5194/acp-10-50752010, 2010

Schwarz, J. P., Spackman, J. R., Gao, R. S., Perring, A. E., Cross, E., Onasch, T. B., Ahern, A., Wrobel, W., Davidovits, P., Olfert, J., Dubey, M. K., Mazzoleni, C., and Fahey, D. W.: The Detection Efficiency of the Single Particle Soot Photometer, Aerosol Sci. Technol., 44, 612-628, 2010.

Seinfeld, J. H. and Pandis, S. N.: Atmos. Chem. Phys., John Wiley
\& Sons, New York, USA, second edn., 43-46, 2006.

Shilling, J. E., Chen, Q., King, S. M., Rosenoern, T., Kroll, J. H., Worsnop, D. R., DeCarlo, P. F., Aiken, A. C., Sueper, D., Jimenez, J. L., and Martin, S. T.: Loading-dependent elemental composition of alpha-pinene SOA particles, Atmos. Chem. Phys., 9, 771-782, doi:10.5194/acp-9-771-2009, 2009.

Simoneit, B.: Biomass burning - review of organic tracers for smoke from incomplete combustion, Appl. Geochem., 17, 129$162,2002$.

Simoneit, B., Schauer, J., Nolte, C., Oros, D., Elias, V., Fraser, M., Rogge, W., and Cass, G.: Levoglucosan, a tracer for cellulose in biomass burning and atmospheric particles, Atmos. Environ., 33, 173-182, 1999.

Simoneit, B. R. T.: Application of molecular marker analysis to vehicular exhaust for source reconciliations, Int. J. Environ. Anal Chem., 22, 203-233, 1985.

Simoneit, B. R. T., Kobayashi, M., Mochida, M., Kawamura, K., and Huebert, B. J.: Aerosol particles collected on aircraft flights over the northwestern Pacific region during the ACE-Asia campaign: Composition and major sources of the organic compounds, J. Geophys. Res.-Atmos., 109, D19S10, doi:10.1029/2004JD004598, 2004.

Stöhr, J.: NEXAFS Spectroscopy, Springer-Verlag, Berlin, 1992.

Subramanian, R., Kok, G. L., Baumgardner, D., Clarke, A., Shinozuka, Y., Campos, T. L., Heizer, C. G., Stephens, B. B., de Foy, B., Voss, P. B., and Zaveri, R. A.: Black carbon over Mexico: the effect of atmospheric transport on mixing state, mass absorption cross-section, and BC/CO ratios, Atmos. Chem. Phys., 10, 219-237, doi:10.5194/acp-10-219-2010, 2010.

Sullivan, A. P., Holden, A. S., Patterson, L. A., McMeeking, G. R., Kreidenweis, S. M., Malm, W. C., Hao, W. M., Wold, C. E., and Collett, J. L.: A method for smoke marker measurements and its potential application for determining the contribution of biomass burning from wildfires and prescribed fires to ambient PM2.5 organic carbon, J. Geophys. Res.-Atmos., 113, D22302, doi:10.1029/2008JD010216, 2008.

Sun, Y., Zhang, Q., Macdonald, A. M., Hayden, K., Li, S. M., Liggio, J., Liu, P. S. K., Anlauf, K. G., Leaitch, W. R., Steffen, A., Cubison, M., Worsnop, D. R., van Donkelaar, A., and Martin, R. V.: Size-resolved aerosol chemistry on Whistler Mountain, Canada with a high-resolution aerosol mass spectrometer during INTEX-B, Atmos. Chem. Phys., 9, 3095-3111, doi:10.5194/acp9-3095-2009, 2009.

Takahama, S., Gilardoni, S., Russell, L. M., and Kilcoyne, A. L. D.: Classification of multiple types of organic carbon composition in atmospheric particles by scanning transmission X-ray microscopy analysis, Atmos. Environ., 41, 9435-9451, 2007.

Takahama, S., Liu, S., and Russell, L. M.: Coatings and clusters of carboxylic acids in carbon-containing atmospheric particles from spectromicroscopy and their implications for cloud-nucleating and optical properties, J. Geophys. Res.-Atmos., 115, D01202, doi:10.1029/2009JD012622, 2010.

Tivanski, A. V., Hopkins, R. J., Tyliszczak, T., and Gilles, M. K.: Oxygenated interface on biomass burn tar balls determined by single particle scanning transmission X-ray microscopy, J. Phys. Chem. A, 111, 5448-5458, 2007.

Turpin, B. J., Saxena, P., and Andrews, E.: Measuring and simulating particulate organics in the atmosphere: problems and prospects, Atmos. Environ., 34, 2983-3013, doi:10.1016/S1352- 
2310(99)00501-4, 2000.

Ulbrich, I. M., Canagaratna, M. R., Zhang, Q., Worsnop, D. R., and Jimenez, J. L.: Interpretation of organic components from Positive Matrix Factorization of aerosol mass spectrometric data, Atmos. Chem. Phys., 9, 2891-2918, doi:10.5194/acp-9-2891-2009, 2009.
Ward, Jr., J.: Hierarchical grouping to optimize an objective function, J. Am. Stat. Assoc., 58, 236-244, 1963.

Zhou, L., Kim, E., Hopke, P., Stanier, C., and Pandis, S.: Mining airborne particulate size distribution data by positive matrix factorization, J. Geophys. Res., 110, D07S19, doi:10.1029/2004JD004707, 2005. 